On the Predictability of Stock Prices: a Case for High and Low Prices

Massimiliano Caporin, Angelo Ranaldo and Paolo Santucci de Magistris

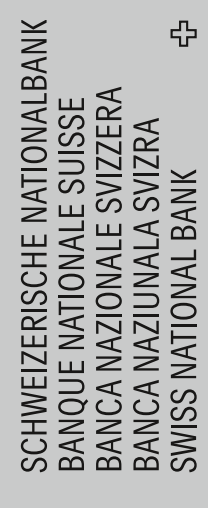


The views expressed in this paper are those of the author(s) and do not necessarily represent those of the Swiss National Bank. Working Papers describe research in progress. Their aim is to elicit comments and to further debate.

\section{Copyright $\odot$}

The Swiss National Bank (SNB) respects all third-party rights, in particular rights relating to works protected by copyright (information or data, wordings and depictions, to the extent that these are of an individual character). SNB publications containing a reference to a copyright ( $\odot$ Swiss National Bank/SNB, Zurich/year, or similar) may, under copyright law, only be used (reproduced, used via the internet, etc.) for non-commercial purposes and provided that the source is mentioned. Their use for commercial purposes is only permitted with the prior express consent of the SNB.

General information and data published without reference to a copyright may be used without mentioning the source.

To the extent that the information and data clearly derive from outside sources, the users of such information and data are obliged to respect any existing copyrights and to obtain the right of use from the relevant outside source themselves.

\section{Limitation of liability}

The SNB accepts no responsibility for any information it provides. Under no circumstances will it accept any liability for losses or damage which may result from the use of such information. This limitation of liability applies, in particular, to the topicality, accuracy, validity and availability of the information.

ISSN 1660-7716 (printed version)

ISSN 1660-7724 (online version)

๑ 2011 by Swiss National Bank, Börsenstrasse 15, P.0. Box, CH-8022 Zurich 


\title{
On the Predictability of Stock Prices: a Case for High and Low Prices*
}

\author{
Massimiliano Caporin $^{\dagger} \quad$ Angelo Ranaldo $^{\ddagger} \quad$ Paolo Santucci de Magistris ${ }^{\S}$
}

\begin{abstract}
Contrary to the common wisdom that asset prices are hardly possible to forecast, we show that high and low prices of equity shares are largely predictable. We propose to model them using a simple implementation of a fractional vector autoregressive model with error correction (FVECM). This model captures two fundamental patterns of high and low prices: their cointegrating relationship and the long memory of their difference (i.e. the range), which is a measure of realized volatility. Investment strategies based on FVECM predictions of high/low US equity prices as exit/entry signals deliver a superior performance even on a risk-adjusted basis.
\end{abstract}

Keywords. high and low prices; predictability of asset prices; range; fractional cointegration; exit/entry trading signals; chart/technical analysis.

JEL Classifications: G11; G17; C53; C58.

*The views expressed herein are those of the authors and not necessarily those of the Swiss National Bank, which does not accept any responsibility for the contents and opinions expressed in this paper. We are very grateful to Adrian Trapletti and Guido Hächler for their support. I also thank Emmanuel Acar, Tim Bollerslev, Fulvio Corsi, Freddy Delbaen, Andreas Fischer and Andrea Silvestrini for their comments. All errors remain our responsibility.

${ }^{\dagger}$ Dipartimento di scienze economiche 'Marco Fanno', Via del Santo 22, Padua, Italy, Tel: +39 049/8274258. Fax: +39 049/8274211. Email: massimiliano.caporin@unipd.it.

${ }^{\ddagger}$ Angelo Ranaldo, Swiss National Bank, Research, Börsenstrasse 15, P.O. Box 2800, Zurich, Switzerland. Email: angelo.ranaldo@snb.ch, Phone: Phone: +41 44 6313826, Fax: +41 446313901.

${ }^{\S}$ Dipartimento di scienze economiche 'Marco Fanno', University of Padua, Italy. Tel.: Tel: +39 049/8273848. Fax: +39 049/8274211. E-mail: paolo.santuccidemagistris@unipd.it. 


\section{Introduction}

The common wisdom in the financial literature is that asset prices are barely predictable (e.g. Fama, 1970, 1991). The rationale for this idea is the Efficient Market Hypothesis (EMH) in which asset prices evolve according to a random walk process. In this paper, we argue that this principle does not hold for the so-called "high" and "low" prices, i.e. the maximum and minimum price of an asset during a given period. By focusing on asset price predictability rather than assessing the EMH paradigm, we address three main questions in this paper: are high and low prices of equity shares predictable? How can we model them? Do forecasts of high and low prices provide useful information for asset and risk management?

There are three respects in which high and low prices can provide valuable information for their predictability. First, they inform people's thinking. Kahneman and Tversky (1979) show that when forming estimates, people start with an initial arbitrary value, and then adjust it in a slow process. In more general terms, behavioral finance studies have shown that agents' behavior generally depends on reference levels. As in a self-reinforcing mechanism, these forms of mental accounting and framing plus previous highs and lows typically represent the reference values for future resistance and support levels.

Second, high and low prices actually shape the decisions of many kinds of market participants, in particular technical analysts. ${ }^{1}$ More generally, any investor using a path-dependent strategy typically tracks the past history of extreme prices. Thus, limit prices in pending stoploss orders often match the most extreme prices in a previous representative period. Moreover, as highlighted in the literature on market microstructure, high and low prices also convey information about liquidity provision and the price discovery process. ${ }^{2}$

Finally, extreme prices are highly informative as a measure of dispersion. The linear difference between high and low prices is known as the range. Since Feller (1951), there have been many studies on the range, starting from the contribution of Parkinson (1980) and Garman and Klass (1980) among many others. ${ }^{3}$ The literature shows that the range-based estimation of volatility is highly statistically efficient and robust with respect to many microstructure frictions (see e.g. Alizadeh, Brandt, and Diebold, 2002).

In order to answer the question of why high and low prices of equity shares are predictable, we present a simple implementation of a fractional vector autoregressive model with error correction (hereafter referred to as FVECM) between high and low prices. The rationale for this modeling strategy is twofold. First, it captures the cointegrating relationship between high and low prices, i.e. they may temporarily diverge but they have an embedded convergent path in the long run. This motivates the error correction mechanism between high and low prices. Second, the difference between the high and low prices, i.e. the range, displays long memory that can be well captured by the fractional autoregressive technique. Combining the cointegration between highs and lows with the long memory of the range naturally leads to model high and low prices in an FVECM framework.

The long-memory feature of the range is consistent with many empirical studies on the predictability of the daily range, a proxy of the integrated volatility, see for example Gallant,

\footnotetext{
${ }^{1}$ Recently, academics documented that technical analysis strategies may succeed in extracting valuable information from typical chartist indicators, such as candlesticks and bar charts based on past high, low, and closing prices (e.g. Lo, Mamaysky, and Wang, 2000), and that support and resistance levels coincide with liquidity clustering ( Kavajecz and Odders-White (2004)). The widespread use of technical analysis especially for short time horizons (intraday to one week) is documented in, e.g., Allen and Taylor (1990). Other papers on resistance levels are Curcio and Goodhart (1992), DeGrauwe and Decupere (1992), and Osler (2000).

${ }^{2}$ For instance, Menkhoff (1998) shows that high and low prices are very informative when it comes to analyzing the order flow in foreign exchange markets.

${ }^{3}$ See also Beckers (1983), Ball and Torous (1984), Rogers and Satchell (1991), Kunitomo (1992), and more recently Andersen and Bollerslev (1998), Yang and Zhang (2000), Alizadeh, Brandt, and Diebold (2002), Brandt and Diebold (2006),Christensen and Podolskij (2007), Martens and van Dijk (2007), Christensen, Zhu, and Nielsen (2009).
} 
Hsu, and Tauchen (1999) which fits a three-factor model to the daily range series to mimic the long-memory feature in volatility, or Rossi and Santucci de Magistris (2009) which finds fractional cointegration between the daily range computed on futures and spot prices. This evidence allows the predictability of variances to be embedded in a model for the mean dynamic of extreme prices. The model we propose thus captures the predictability of extreme prices by means of the predictability of second-order moments, which is a widely accepted fact since the seminal contribution of Engle (1982) and following the ARCH models literature. We thus provide an affirmative answer to the first and second questions initially posed: first, there is compelling evidence of the predictability of high and low prices; second, it suffices to apply a linear model that captures the fractional cointegration between the past time series of highs and lows.

To answer our third question, i.e. do forecasts of high and low prices provide useful information for asset management, we analyze intraday data of the stocks forming the Dow Jones Industrial Average index over a sample period of eight years. The sample period is pretty representative since it covers calm and liquid markets as well as the recent financial crisis. We find strong support for the forecasting ability of FVECM, which outperforms any reasonable benchmark model. We then use the out-of-sample forecasts of high and low prices to implement some simple trading strategies. The main idea is to use high and low forecasts to determine entry and exit signals. Overall, the investment strategies based on FVECM predictions deliver a superior performance even on a risk-adjusted basis.

The present paper is structured as follows. Section 2 discusses the integration and cointegration properties of high and low daily prices in a non-parametric setting. At this stage, our analysis is purely non-parametric and employs the most recent contributions of the literature (such as Shimotsu and Phillips (2005), Robinson and Yajima (2002), and Nielsen and Shimotsu (2007)). Section 3 presents the FVECM that is an econometric specification consistent with the findings of the previous section, i.e. the fractional cointegration relationship between high and low prices. After reporting the estimation outputs, Section 4 provides an empirical application of the model forecast in a framework similar to the technical analysis. Section 5 concludes the paper.

\section{Integration and Cointegration of Daily High and Low Prices}

Under the EMH, the daily closing prices embed all the available information. As a result, the best forecast we could make for the next day's closing price is today's closing price. This translates into the commonly accepted assumption of non-stationarity for the closing prices or, equivalently, the hypothesis that the price evolution is governed by a random walk process (which is also referred to as an integrated process of order 1, or a unit-root process). Consequently, price movements are due only to unpredictable shocks. ${ }^{4}$ Furthermore, the random walk hypothesis is also theoretically consistent with the assumption that price dynamics are driven by a geometric Brownian motion, which implies normally distributed daily log-returns. Finally, the EMH implies that the prices are not affected by some short-term dynamics such as autoregressive (AR) or moving average (MA) patterns. ${ }^{5}$

However, it is also commonly accepted that daily log-returns strongly deviate from the hypothesis of log-normality, thus casting some doubts on the law of motion hypothesis, in particular with respect to the distributional assumption. In fact, extreme events are more likely to occur compared with the Gaussian case, and returns are asymmetric, with a density shifted to the

\footnotetext{
${ }^{4}$ In more general terms, if the EMH holds, future prices cannot be predicted using past prices as well as using past values of some covariates. We do not consider here the effects of the introduction of covariates, but focus on the informative content of the price sequence. As a result, we focus on the "weak-form efficiency" as presented in Fama (1970).

${ }^{5}$ The short-term dynamic could co-exist with the random walk within an ARIMA structure, where autoregressive (AR) and moving average (MA) terms are coupled with unit root (integrated) components.
} 
left (negative asymmetry). Many studies analyze market efficiency by testing the stationarity of daily closing prices or market values at given points of time, see Lim and Brooks (2011). ${ }^{6}$

Although market efficiency should hold for any price, by their very nature high/low prices differ from closing prices in two main respects. First, liquidity issues are more relevant for high and low prices. Intuitively, high (low) prices are more likely to correspond to ask (bid) quotes, thus transaction costs and other frictions such as price discreteness, the tick size (i.e. the minimal increments) or stale prices might represent disturbing factors. Second, highs and lows are more likely to be affected by unexpected shocks such as (unanticipated) public news announcements. Then, some aspects such as market resiliency and quality of the market infrastructure can be determinant. In view of these considerations, we pursue a conservative approach by considering the predictability of highs and lows per se as weak evidence of market inefficiency. A more rigorous test is the analysis of the economic implications arising from the predictability of highs and lows. More specifically, we assess whether their prediction provides superior information to run outperforming trading rules.

We should also stress that this attempt will be limited to the evaluation of the serial correlation properties of those series, without the inclusion of the information content of other covariates. Our first research question is thus to analyze the stationarity properties of daily high and daily low prices in order to verify whether the unpredictability hypothesis is valid if applied separately to the two series. If the unpredictability hypothesis holds true, both high and low prices should be driven by random walk processes, and should not have relevant short-term dynamic components (they should not be governed by ARIMA processes). To tackle this issue we take a purely empirical perspective: at this stage we do not make assumptions either on the dynamic process governing the evolution of daily high and low, nor on the distribution of prices, log-prices or returns over high and low. Such a choice does not confine us within the unrealistic framework of geometric Brownian motions, and, more relevantly, does not prevent us from testing the previous issues. In fact, when analyzing the non-stationarity of price sequences, a hypothesis on the distribution of prices, log-prices or returns is generally not required. Given the absence of distributional hypotheses and of assumptions on the dynamic, we let the data provide some guidance. We thus start by analyzing the serial correlation and integration properties of daily high and low prices. Furthermore, given the link between high and low prices and the integrated volatility presented in the introduction, we also evaluate the serial correlation and integration of the difference between high and low prices, the range. In the empirical analyses we focus on the 30 stocks belonging to the Dow Jones Industrial Average index as of end of December 2010.

We consider the daily high $\log$-price, $p_{t}^{H}=\log \left(P_{t}^{H}\right)$, and the daily low log-price, $p_{t}^{L}=$ $\log \left(P_{t}^{L}\right)$. Our sample data covers the period January 2, 2003 to December 31, 2010, for a total of 2015 observations. The plots of the daily high and low prices show evidence of a strong serial correlation, typical of integrated processes, and the Ljung-Box test obviously strongly rejects the null of no correlation for all lags. ${ }^{7}$ Therefore, we first test the null hypothesis of unit root for the daily log-high, log-low and range by means of the Augmented Dickey Fuller $(A D F)$ test. In all cases, the ADF tests cannot reject the null of unit root for the daily log-high and log-low prices. ${ }^{8}$ This result is robust to the inclusion of the constant and trend, as well as different choices of lag. The outcomes obtained by a standard approach suggest that the daily high and daily low price sequences are integrated of order 1 or, equivalently, that they are governed by random walk processes (denoted as $\mathrm{I}(1)$ and $\mathrm{I}(0)$, respectively). At first glance, this finding seems to support the efficient market hypothesis. This is further supported by the absence of a long- and short-range dependence on the first differences of daily high and daily low log-prices. Moreover, there is clear evidence that daily range is not an I(1) process, but

\footnotetext{
${ }^{6}$ To our knowledge, Cheung (2007) represents the only noticeable exception that analyzes high and low prices.

${ }^{7}$ Results not reported but available on request.

${ }^{8}$ Using standard testing procedures based on the ADF test, we also verified that the integration order is 1 , given that on differenced series the ADF test always rejects the null of a unit root.
} 
should be considered an $\mathrm{I}(0)$ process. Based on these results, one can postulate that daily high and daily low prices are cointegrated, since there exists a long-run relation between highs and lows that is an $\mathrm{I}(0)$ process. However, this finding must be supported by proper tests, since the existence of a cointegrating relation between daily high and daily low potentially allows for the construction of a dynamic bivariate system which governs the evolution of the two series, with a possible impact on predictability. These results confirm the findings in Cheung (2007). Besides the previous result, Andersen and Bollerslev (1997) and Breidt, Crato, and de Lima (1998), among others, find evidence of long memory (also called long range dependence) in asset price volatility. This means that shocks affecting the volatility evolution produce substantial effects for a long time. In this case, volatility is said to be characterized by a fractional degree of integration, due to the link between the integration order and the memory properties of a time series, as we will see in the following. In our case, the autocorrelation function, $A C F$, in Figure 1 seems to suggest that the daily range is also a fractionally integrated process, provided that it decays at a slow hyperbolic rate. In particular, the ACF decays at a slow hyperbolic rate, which is not compatible with the $\mathrm{I}(0)$ assumption made on the basis of ADF tests. Unfortunately, the $\mathrm{ADF}$ is designated to test for the null of unit root, against the $\mathrm{I}(0)$ alternative, and it is also well known, see Diebold and Rudebusch (1991), that the ADF test has very low power against fractional alternatives. Therefore, we must investigate the integration order of daily high and low prices and range in a wider sense, that is in the fractional context. We also stress that the traditional notion of cointegration is not consistent with the existence of long-memory. In order to deeply analyze the dynamic features of the series at hand, we resort to more recent and nonstandard tests for evaluating the integration and cointegration orders of our set of time series. Our study thus generalizes the work of Cheung (2007) since it does not impose the presence of the most traditional cointegration structure, and it also makes the evaluation consistent with the findings of long memory in financial data.

We thus investigate the degree of integration of the daily high and low prices, and of their difference, namely the range, in a fractional or long-memory framework. This means that we assume that we observe a series, $y_{t} \sim I(d), d \in \Re$, for $t \geq 1$, is such that

$$
(1-L)^{d} y_{t}=u_{t}
$$

where $u_{t} \sim I(0)$ and has a spectral density that is bounded away from zero at the origin. Differently from the standard setting, the integration order $d$ might assume values over the real line and is not confined to integer numbers. Note that if $d=1$ the process collapses on a random walk, whereas if $d=0$ the process is integrated of order zero, and thus stationary. The econometrics literature on long-memory processes distinguishes between type I and type II fractional processes. These processes have been carefully examined and contrasted by Marinucci and Robinson (1999), and Davidson and Hashimzade (2009). The process $y_{t}$ reported above is a type II fractionally integrated process, which is the truncated version of the general type I process, since the initial values, for $t=0,-1,-2, \ldots$ are supposed to be known and equal to the unconditional mean of the process (which is equal to zero)..$^{9}$ In this case, the term $(1-L)^{d}$ results in the truncated binomial expansion

$$
(1-L)^{d}=\sum_{i=0}^{T-1} \frac{\Gamma(i-d)}{\Gamma(-d) \Gamma(i+1)} L^{i}
$$

so that the definition in (1) is valid for all $d$, see Beran (1994) among others. In particular, for $d<0$, the process is said to be anti-persistent, while for $d>0$ it has long memory. When dealing with high and low prices, our interest refers to the evaluation of the integration order $d$ for both high and low, as well as of the integration order for the range. Furthermore, if the daily high and daily low time series have a unit root while the high-low range is a stationary

\footnotetext{
${ }^{9}$ In contrast, type I processes assume knowledge of the entire history of $y_{t}$.
} 
but long-memory process, a further aspect must be clarified. In fact, as already mentioned, the presence of a stationary linear combination (the high-low range) of two non-stationary series opens the door to the existence of a cointegrating relation. However, the traditional tests of cointegration are not consistent with the memory properties of the high-low range. Therefore, we chose to evaluate the fractional cointegration across the daily high and daily low time series.

In the context of long-memory processes, the term fractional cointegration refers to a generalization of the concept of cointegration, since it allows linear combinations of $I(d)$ processes to be $I(d-b)$, with $0<b \leq d$. The term fractional cointegration underlies the idea of the existence of a common stochastic trend, that is integrated of order $d$, while the short period departures from the long-run equilibrium are integrated of order $d-b$. Furthermore, $b$ stands for the fractional order of reduction obtained by the linear combination of $I(d)$ variables, which we call cointegration gap. We first test for the presence of a unit root in the high and low prices, so that $d=1$, and, as a consequence, the fractional integration order of the range becomes $1-b$. In order to test the null hypothesis of a unit root and of a fractional cointegration relation between daily high and low prices, we consider a number of approaches and methodologies. First, we estimate the fractional degree of persistence of the daily high and low prices by means of the univariate local exact Whittle estimator of Shimotsu and Phillips (2005). Notably, their estimator is based on the type II fractionally integrated process. The univariate local exact Whittle estimators for high and lows ( $\hat{d}_{H}$ and $\hat{d}_{L}$, respectively) minimizes the following contrast function

$$
Q_{m_{d}}\left(d_{i}, G_{i i}\right)=\frac{1}{m_{d}} \sum_{j=1}^{m_{d}}\left[\log \left(G_{i i} \lambda_{j}^{-2 d}\right)+\frac{1}{G_{i i}} I_{j}\right] \quad i=H, L
$$

which is concentrated with respect to the diagonal element of the $2 \times 2$ matrix $G$, under the hypothesis that the spectral density of $U_{t}=\left[\Delta^{d_{H}} p_{t}^{H}, \Delta^{d_{L}} p_{t}^{L}\right]$ satisfies

$$
f_{U}(\lambda) \sim G \text { as } \lambda \rightarrow 0 .
$$

Furthermore, $I_{j}$ is the coperiodogram at the Fourier frequency $\lambda_{j}=\frac{2 \pi j}{T}$ of the fractionally differenced series $U_{t}$, while $m_{d}$ is the number of frequencies used in the estimation. The matrix $G$ is estimated as

$$
\hat{G}=\frac{1}{m_{d}} \sum_{j=1}^{m_{d}} \operatorname{Re}\left(I_{j}\right)
$$

where $\operatorname{Re}\left(I_{j}\right)$ denotes the real part of the coperiodogram. Table 1 reports the exact local Whittle estimates of $d^{H}$ and $d^{L}$ for all the stocks under analysis. As expected, the fractional orders of integration are high and generally close to 1 . Given the estimates for the integration orders, we test for equality according to the approach proposed in Nielsen and Shimotsu (2007) that is robust to the presence of fractional cointegration. The approach resembles that of Robinson and Yajima (2002), and starts from the fact that the presence or absence of cointegration is not known when the fractional integration orders are estimated. Therefore, Nielsen and Shimotsu (2007) propose a test statistic for the equality of integration orders that is informative independently from the existence of the fractional cointegration. In the bivariate case under study, the test statistic is

$$
\widehat{T}_{0}=m_{d}(S \hat{d})^{\prime}\left(S \frac{1}{4} \hat{D}^{-1}(\hat{G} \odot \hat{G}) \hat{D}^{-1} S^{\prime}+h(T)^{2}\right)^{-1}(S \hat{d})
$$

where $\odot$ denotes the Hadamard product, $\hat{d}=\left[\hat{d}^{H}, \hat{d}^{L}\right], S=[1,-1]^{\prime}, h(T)=\log (T)^{-k}$ for $k>0$, $D=\operatorname{diag}\left(G_{11}, G_{22}\right)$. If the variables are not cointegrated, that is the cointegration rank $r$ is zero, $\widehat{T}_{0} \rightarrow \chi_{1}^{2}$, while if $r \geq 1$, the variables are cointegrated and $\widehat{T}_{0} \rightarrow 0$. A significantly large value of $\widehat{T}_{0}$, with respect to the null density $\chi_{1}^{2}$, can be taken as an evidence against the equality of the integration orders. The estimation of the cointegration rank $r$ is obtained by calculating the eigenvalues of the matrix $\hat{G}$. Since $G$ does not have full rank when $p_{t}^{H}$ and $p_{t}^{L}$ 
are cointegrated, then $G$ is estimated following the procedure outlined in Nielsen and Shimotsu (2007, p. 382) which involves a new bandwidth parameter $m_{L}$. In particular, $\hat{d}_{H}$ and $\hat{d}_{L}$ are obtained first, using (3) with $m_{d}$ as bandwidth. Given $\hat{d}$, the matrix $G$ is then estimated, using $m_{L}$ periodogram ordinates in (5), such that $m_{L} / m_{d} \rightarrow 0$. The table reports the estimates for $m_{d}=T^{0.6}$ and $m_{L}=T^{0.5}$, while results are robust to all different choices of $m_{d}$ and $m_{L}$.

Let $\hat{\delta}_{i}$ be the $i$ th eigenvalue of $\hat{G}$, it is then possible to apply a model selection procedure to determine $r$. In particular,

$$
\hat{r}=\arg \min _{u=0,1} L(u)
$$

where

$$
L(u)=v(T)(2-u)-\sum_{i=1}^{2-u} \hat{\delta}_{i}
$$

for some $v(T)>0$ such that

$$
v(T)+\frac{1}{m_{L}^{1 / 2} v(T)} \rightarrow 0 .
$$

The previous tests are concordant in suggesting that the integration order of $p_{t}^{H}$ and $p_{t}^{L}$ are equal and close to unity. This is the case for 26 out of 30 equities of the DJIA index. Furthermore, Table 1 shows that $L(1)<L(0)$ in all cases considered, and this can be taken as strong evidence in favor of fractional cointegration between $p_{t}^{H}$ and $p_{t}^{L}$, so that equation 8 is minimized in correspondence of $r=1$. The results reported are relative to the case where $v(T)=m_{L}^{-0.35}$ and remain valid for alternative choices of $v(T)$ (not reported to save space). Note that, in the bivariate case, equation 8 is minimized if $v(T)>\min \left(\delta_{i}\right)$, where $\min \left(\delta_{i}\right)$ is the smallest eigenvalue of $\hat{G}$ (or alternatively of the estimated correlation matrix $\hat{P}=\hat{D}^{-1 / 2} \hat{G} \hat{D}^{-1 / 2}$ ). Provided that the correlation between $p^{H}$ and $p^{L}$ is approximately 1 in all cases, then $\hat{P}$ is almost singular and the smallest eigenvalue of $\hat{P}$ is very close to 0 . Therefore $v(T) \approx v(T)-\min \left(\delta_{i}\right)>0$ and this explains why $L(1)$ has a similar value across all the assets considered. As a preliminary data analysis, we also carry out the univariate Lagrange Multiplier (LM) test of Breitung and Hassler (2002) to verify the null hypothesis of unit roots against fractional alternatives. Unfortunately, we cannot use the extension of Nielsen (2005), since the multivariate LM test of fractional integration order, which is based on the type II fractionally integrated process, always rejects the null of $d=1$, when series are fractionally cointegrated. Therefore, it is impossible to know if the null has been rejected due to a cointegration relation or because one of the variables is $I(1)$. Table 1 reports the $p$-values of the univariate LM tests of Breitung and Hassler (2002) for $p_{t}^{L}$ and $p_{t}^{H}$. In all cases the null hypothesis cannot be rejected at the $5 \%$ significance level, meaning that the high and low log-prices can be considered unit root processes, so that $\left[\Delta p_{t}^{H}, \Delta p_{t}^{H}\right] \sim I(0)$. As a further check, provided that the daily range is an estimate of the daily integrated volatility (Parkinson (1980)), and given several empirical studies showing that the daily realized range has long-memory, we consider the evaluation of the fractional parameter of the daily range series. Note that we refer to the range, $R_{t}=p_{t}^{H}-p_{t}^{L}$, as the rescaled root square of the Parkinson estimator, that is $R G_{t}^{2}=0.361 \cdot\left(p_{t}^{H}-p_{t}^{L}\right)^{2}$. The Breitung and Hassler (2002) test on $R_{t}$ confirms the results of the Nielsen and Shimotsu (2007) procedure, since the linear combination $p_{t}^{H}-p_{t}^{L}$ significantly reduces the integration order in almost all cases, and the local exact Whittle estimates of $d^{R}$ are approximately $0.6-0.7$ in all cases, that is in the non-stationary region. Furthermore, the LM test for $R_{t}$ rejects the null of unit root in 28 out of 30 cases at $10 \%$ significance level. As expected, the range has a fractional integration order that is significantly below 1 , and in the next section we will show how to incorporate this evidence in a parametric model which exploits the long-run relationship between daily high and low prices. These results are in line with the well-known stylized fact that volatility of financial returns is characterized by long-range dependence, or long memory, see, for instance, Baillie (1996), Bollerslev and Mikkelsen (1996), Dacorogna, Muller, Nagler, Olsen, and Pictet (1993), Ding, Granger, and Engle (1993), Granger and Ding (1996), Andersen, Bollerslev, Diebold, and Ebens 
(2001). In a recent contribution, Rossi and Santucci de Magistris (2009) find evidence of long memory and fractional cointegration between the daily ranges of the spot and futures prices of the S\&P 500 index.

\section{Modeling Daily High and Low Prices}

As we showed in the previous section, the high and low prices have an embedded convergent path in the long run, so that they are (fractionally) cointegrated. For intuitive reasons ${ }^{10}$, we expect that high and low prices can deviate in the short run from their long-run relation. The concept of cointegration has been widely studied during the last three decades, since the original paper by Granger (1981). Most of the analysis has concentrated on the special case where a linear (or nonlinear) combination of two or more $I(1)$ variables is $I(0)$. Tests for $I(1) / I(0)$ cointegration are carried out in a regression setup, as proposed by Engle and Granger (1987), or investigate the rank of the cointegration matrix in a system of equations following the Johansen (1991) procedure. A similar approach has been followed by Cheung (2007). When a cointegration relation exists across two variables, the bivariate system can be re-written in a Vector Error Correction (VEC) form, where the first difference of the cointegrated variables is a function of the cointegrating relation. Such a model has an interesting economic interpretation since deviations from the long-run equilibrium (given by the cointegrating relation) give rise to an adjustment process that influences the future values of the modeled variables. In our framework, changes in the actual high and low prices that make them inconsistent with the long-run relation will produce an effect on future high and low prices. However, the long memory must also be taken into account, differently from what has been considered in Cheung (2007). In a recent contribution, Johansen (2008) proposes a generalization of the VEC model to the fractional case. Such an extension allows for a representation (through a so-called Granger representation theorem) which, in turn, enables us to distinguish between cofractional relations and common trends. Johansen (2008) suggests studying the fractional cointegration relation in the following system representation

$$
\Delta^{d} X_{t}=\left(1-\Delta^{b}\right)\left(\Delta^{d-b} \alpha \beta^{\prime} X_{t}-\mu\right)+\sum_{j=1}^{K} \Gamma_{j} \Delta^{d} L_{b}^{j} X_{t}+\epsilon_{t}
$$

which is based on the new generalized lag operator $L_{b}=1-(1-L)^{b}$. In our set-up, the vector $X_{t}$ includes the daily high and low log-prices, $X_{t}=\left(p_{t}^{H}, p_{t}^{L}\right)^{\prime}$, and $\epsilon_{t}=\left(\epsilon_{t}^{H}, \epsilon_{t}^{L}\right)^{\prime}$ is assumed to be i.i.d. with finite eight moments, mean zero and variance $\Omega$. Furthermore, $\alpha=$ $\left(\alpha_{H}, \alpha_{L}\right)$ is the vector of the loadings, while $\beta=(1, \gamma)$ is the cointegration vector. The first term on the right can be represented as $\alpha\left(1-\Delta^{b}\right) \Delta^{d-b}\left(p_{t}^{H}+\gamma p_{t}^{L}-\mu\right)$ where the core component $\left(1-\Delta^{b}\right) \Delta^{d-b}\left(p_{t}^{H}+\gamma p_{t}^{L}-\mu\right)$ defines the cointegration relation. Differently, the element $\alpha_{i}$ in the vector $\alpha$ measures the single period response of variable $i$ to the shock on the equilibrium relation. In the following, we restrict the cointegration parameter $\gamma$ to be equal to -1 , so that the cointegration relation can be interpreted in terms of the high-low range. We note that in preliminary estimates where this restriction was not imposed, the estimated cointegration parameter was generally very close to one, and we were not rejecting the null of $\gamma=1$. Moreover, imposing the condition $d=1$ in model (10) implies that, following the definition of Hualde and Robinson (2010), in the case of strong fractional cointegration, i.e. $b>1 / 2$, the range would be stationary and integrated of order $d-b<0.5$. On the other hand, the case of weak fractional cointegration, where $0<b<1 / 2$ see Hualde and Robinson (2010), leads to a non-stationary fractionally integrated range. We also introduce a constant term, $\mu$, in the cointegration relation, which represents the mean value of the range; $\mu$ must be positive, provided

\footnotetext{
${ }^{10}$ High and low prices can deviate temporarily because of information motives, liquidity factors or other microstructure effects such as bid-ask spread bounces, price discreteness, trading pressure.
} 
that $p_{t}^{H} \geq p_{t}^{L}$ by definition. Assuming that the rank of the matrix $\alpha \beta$, the cointegration rank $r$, is known already, model (10) is estimated following the procedure outlined in Lasak (2008) and Johansen and Nielsen (2010a). In particular, model (10) is estimated via a maximum likelihood technique analogous to that developed by Johansen (1991) for the standard VEC model ${ }^{11}$. The asymptotic distribution of the FVECM model estimators is studied in Lasak (2008) and Johansen and Nielsen $(2010 \mathrm{~b}, \mathrm{a})$, while this estimation procedure has been employed by Rossi and Santucci de Magistris (2009), which show the finite sample properties of the estimators through a Monte Carlo simulation. In a recent contribution, Johansen and Nielsen (2011) show that the asymptotic distribution of all the FVECM model parameters is Gaussian when $b<1 / 2$. On the other hand, when $b>1 / 2$, the asymptotic distribution of $\beta$ is mixed Gaussian, while the estimators of the remaining parameters are Gaussian. On the basis of the results in the previous section, it seems natural to estimate model (10) on the log high and low prices for the 30 stocks under analysis. One lag in the generalized autoregressive term is assumed to be sufficient in all cases for a good description of the short term component. Table 2 reports the estimation results of model (10) on the 30 series. The estimated parameter $b$ is lower than 0.5 in 27 cases, meaning that, as expected, daily range is generally non-stationary. In particular, the estimated degree of long range dependence of daily range implied by the FVECM model is between 0.4611 and 0.7467 , meaning that the persistence of the range is very high, while the null hypothesis $d=1$ cannot be rejected in most cases. It is noteworthy to stress that the estimated degree of long memory of the range which is implied by the FVECM model is very close to the values obtained with the semiparametric estimators, in Section 2. Moreover, $\alpha_{H}$ and $\alpha_{L}$ are significant and with the expected signs, so that it is possible to conclude that high and low prices are tied together by a common long-memory stochastic trend toward which they converge in the long run at significant rates.

Interestingly, the deviations from the attractor (the long-run relation) have an economic interpretation in terms of volatility proxy, that is the range. Therefore, a parametric model for the high-low prices incorporates significant information on the degree of dispersion of the prices. Hence, we are able to exploit the long-memory feature of the price dispersion in order to obtain better forecasts of future high and low log-prices based on past values. Figure 1 reports the high and low log-prices series of IBM and the common stochastic trend constructed from the estimates of model 10 and the Granger representation theorem for fractional VAR in Johansen (2008). It is also clear that the common stochastic trend closely follows the dynamics of the high and low log-prices, provided that they are tied together by a strong cointegration relation. The deviations from the long run relationship, which is the high-low distance or range, are also plotted. The range is a highly persistent series characterized by long periods above or below the unconditional mean. For example, the recent financial crisis in 2008-2009 is characterized by a larger discrepancy between the high and low prices, that is the result of a higher market risk. In the next section, we will show a possible trading strategy that can benefit from better forecasts of daily high-low bands.

\section{Forecasting and Trading}

Given the estimates of model (10), a natural exercise would be based on the forecasts of the high and low prices, using them to implement a trading strategy based on the predicted so-called high-low bands. Our focus is purely illustrative, and we provide a reasonable application of our modeling approach, thereby extending the study of Cheung (2007) in that direction. In doing so, we consider an expanding estimation period, which is used to evaluate the model and produce the one-step-ahead forecasts. We base our analysis on a subset of 20 assets of the Dow Jones index, for which we dispose of high frequency prices (i.e. one-minute frequency) for a total of 390 intradaily prices per day. The sample covers the period from January 2, 2003 to

\footnotetext{
${ }^{11}$ The VEC is obtained as a special case of the FVECM when $d$ and $b$ are fixed to be equal to 1
} 
December 31, 2009, for a total of $T=1762$ observations. We provide out-of-sample forecasts for the last 251 sample data points, the year 2009. Therefore, the estimation sample length includes a minimum of $S=1511$ observations and a maximum of $S=T-1$ data points. At each step, model (10) is estimated on the first $S$ observations, and a one-step-ahead forecast of the high and low prices is obtained; we call these forecasts $F C$ bands. Note that, in order to guarantee that the predicted high-low bands are robust to the overnight activity, the overnight return $\log O_{t}-\log C_{t-1}$ is included in model (10) as an additional explanatory variable $\left(O_{t}\right.$ and $C_{t-1}$ are the opening and closing prices, respectively). The introduction of the overnight return $\log$ mimics the regular operating activity of a trader who, using the model, produces the day $t$ forecasts for high and low, including the opening price of time $t$ in the information set. Given the bands, the trader uses them within day $t$ regular trading hours. Figure 2 plots the Japanese candlesticks, based on the observed prices of JPM, with the corresponding predicted high-low bands. It is clear that the $F C$ bands provide a better out-of-sample fit of the high-low dispersion with respect to the high-low bands based on a 5-day moving average of high and low, $M A_{5}$, which represents a tool often used by technical analysts. Table 3 reports the $p$-values of the Diebold and Mariano (1995) test for the out-of -ample forecasts of the high and low log-prices, obtained using the FVECM. As competing models we chose the random walk, $R W$, the 5-day moving average, $M A_{5}$, and the 22-day moving average, $M A_{22}$, which correspond to weekly and monthly averages respectively. ${ }^{12}$ We correct the predicted high-low bands of $R W, M A_{5}$ and $M A_{22}$ by adding the difference between the opening price of day $t, O_{t}$, and the closing price of day $t-1, C_{t-1}$. Such a choice realigns those competing forecasts with the information set used in the FVECM model where the opening price of time $t$ is taken into account. The Diebold and Mariano (1995) test for the forecasting superiority of FVECM is carried out focusing on the mean squared error (MSE) and on the mean absolute error (MAE) of the forecasts, where the error of model $i$ at date $t$ is defined as the difference, $\epsilon_{i, t}$, between the observed high in the period $t+1^{13}$, and the corresponding forecast provided by model $i$ :

$$
\epsilon_{t+1, i}^{H}=p_{t+1}^{H}-\hat{p}_{t+1, i}^{H} \quad i=F V E C M, R W, M A_{5}, M A_{22}
$$

Specifically, the interest is on the measure of the relative forecasting performance of the different model specifications, testing the superiority of model $i$ over FVECM, which is the benchmark, with a $t$-test for the null hypothesis of a zero mean in

$$
\begin{aligned}
\epsilon_{t+1, F V E C M}^{2}-\epsilon_{t+1, i}^{2} & =c_{i}+\nu_{t} \\
\left|\epsilon_{t+1, F V E C M}\right|-\left|\epsilon_{t+1, i}\right| & =d_{i}+\xi_{t}
\end{aligned}
$$

where negative estimates of $c_{i}$ and $d_{i}$ indicate support for the $F V E C M$, provided that all models are compared to the FVECM. The Diebold and Mariano (1995) test is the $t$-statistics for the nullity of the estimates of $c_{i}$ and $d_{i}$. Overall, Table 3 , depicts a situation where the forecast errors associated with the FVECM are significantly smaller than those of the competing models. As expected, the $p$-value of the test for $M A_{5}$ and $M A_{22}$ is highly significant in all cases. This is due to the fact that moving averages are used in practice to identify local trends in the prices and not for a point estimate of the prices. On the other hand, for what concerns the $R W$ model, the $t$-test based on MSE is always negative and the $p$-value is often lower than $5 \%$ for both the $p_{t}^{H}$ and $p_{t}^{L}$. This result suggests that the fractional cointegration model significantly improves the forecasts of high and low log prices, with respect to the model that, consistently with the strong efficiency of the markets, assumes that the best forecast of future prices is the actual price.

We then implement two simple trading rules that make use of the model outcomes. At first, we consider a trading rule based on the predicted high-low bands. We define buy and sell

\footnotetext{
${ }^{12}$ The alternative specifications all consider separately the high and low prices for the construction of high and low bands. By contrast, our model provides the high and low forecasts within a unified framework.

${ }^{13}$ Analogously for the low $\log$-price.
} 
signals comparing the intradaily evolution of the equity price and the high-low bands. If the price crosses the high band, we interpret it as a buy signal. Conversely, if the price crosses the low band we have a sell signal, see Murphy (1999). This can be interpreted as a trend-following strategy, where the upper line is used as a bull-trendline in a uptrend, while the lower line is used as a bear-trendline in a downtrend. We also implement the contrarian strategy: if the price crosses the high band, we interpret it as a sell signal. Conversely, if the price crosses the low band we have a buy signal.

It is therefore possible to carry out a realistic trading strategy based on the high-low bands, as described above. In particular, the previous rules define the creation of long or short positions. Those positions created within day $t$ can be closed or maintained in the following days. Once we enter a new position, two additional bands are created in order to guarantee a desired minimum level of profit or a maximum acceptable loss. These additional bands, called the stop-loss and take-profit bands, are proportional to the high-low distance and are created as follows. Suppose that we have a trend-following strategy, and the predicted upper bound, $\hat{P}_{t}^{H}$, is crossed by the price at a given time $t<\tau_{0}<t+1$. In this case, we open a long position and the stop-loss and take-profit thresholds are created as $S L_{t}=\hat{P}_{t}^{H}-\delta \hat{R}_{t}$ and $T P_{t}=\hat{P}_{t}^{H}+\delta \hat{R}_{t}$, respectively, where $\delta$ determines the size of the new bands and $\hat{R}_{t}=\hat{P}_{t}^{H}-\hat{P}_{t}^{L}$ is the predicted daily range. If the price crosses the $S L_{t}$ or $T P_{t}$ in $\tau_{0}<\tau<t+1$, then the long position is closed. On the other hand, if an open position is not closed during day $t$, then it is maintained until $t+1$. By design, positions can also be closed at the opening price for two possible reasons: first, during the market closing period, relevant news might be released with a potentially elevating impact on prices; second, the FVECM model does not guarantee that the opening price at time $t+1$ is inside the high/low bands of time $t+1$. Suppose that at time $t$ we have an opened long position in a trend following strategy. At the beginning of $t+1$, the position is closed if $O_{t+1}<\max \left(\left[\hat{P}_{t+1}^{L} ; S L_{t}\right]\right)$ or if $O_{t+1}>\min \left(\left[\hat{P}_{t+1}^{H} ; T P_{t}\right]\right)$. Such a choice allows us to avoid too risky strategies which might be taken in case of large variations of the prices over two consecutive days. If a position is not closed during the market opening, then $\hat{P}_{t+1}^{L}$ and $\hat{P}_{t+1}^{H}$ are used as predicted H-L bands for $t+1$. Similarly we can define stop-loss and take-profit bands for the short positions and for the contrarian strategy. The payoffs of this trading system, based on two couples of high-low bands, are reported in Table 4. In order to consider a realistic trading strategy, it is assumed that an initial amount, $A_{0}$, of 20,000 US dollars can be invested in the strategy. A fixed cost of 5 dollars is charged on each transaction. During day $t$, the investor can buy or sell an amount of stocks that is equal to $N_{t}=\left[A_{t} / P_{\tau_{0}}\right]$, where $[x]$ indicates the nearest integer less than or equal to $x$ and $\tau_{0}$ is the time in which the price crosses the bands.

It is immediately evident that the strategies are symmetric, so that when the trend-following strategy produces a positive payoff, then in most cases the corresponding payoff of the contrarian strategy is lower than 20000 dollars. We notice in general that, across the strategies considered, the payoff from the contrarian strategy is generally higher than the payoff obtained with trend following. This is probably due to the fact that, when the price exceeds a given threshold, there is a higher probability that it will revert, tending to move toward the initial value, rather than moving further toward more extreme values. The reverting behavior of the extremes has also been noted by Cheung (2007).

Relatively to the other bands employed, the $F C$ bands have similar performances in terms of final outcome. The $F C$ bands provide less frequently the worst performance with respect to the alternative choices. Moreover, when the contrarian strategy is employed with the $F C$ bands, we observe 12 and 11 positive outcomes with $\delta=0.25$ and $\delta=0.5$. In particular, the strategy based on the $F C$ bands has good relative performances when the contrarian strategy is applied with $\delta=0.5$, which increases the probability of maintaining the position opened until $t+1$. In that case, the $F C$ bands have the best performances in 7 cases. Except for the case of $B A C$ and $J P M$, the profits and losses associated with $F C$ are rarely above 3000 dollars (or less than $-3000)$, so we can conclude that in general it seems that the payoff variability associated with 
$F C$ is lower than the variability associated with the other strategies.

An alternative trading system could be based on a different construction of the bands. Now we focus on the predictions of the model (10) as a possible way of recovering a forecast of the range, $\hat{R}_{t}$. This is automatically obtained by the difference between the predicted high and low prices. Therefore a range-based strategy can be employed. For $M A_{5}$ and $M A_{22}$, these are the averages of the daily range with different horizons, while $R W$ simply takes the range at time $t-1$ as the predicted range at time $t$. In this case, the daily H-L bands for day $t$, are centered on the open price, so that the upper band is equal to $O_{t}+\hat{R}_{t}$ and $O_{t}-\hat{R}_{t}$. Therefore, the size of the band is $2 \hat{R}_{t}$. Once the bands have been created, the trend-following (or the contrarian) strategy could be implemented similarly to as described above, with the corresponding $S L$ and TP bands which are constructed with $\delta=0.5$. In this case, the position, eventually opened during day $t$, is not maintained until $t+1$ and must be closed before (or in correspondence of) the last trade of day $t$. Table 5 reports the results of a contrarian strategy based on the daily range bands. Table 5 reports the value of the investment at the end of the sample, say on December 31, 2009. In 12 out of 20 cases the strategy based on the range, obtained from model (10), reports positive profits, while the strategy based on buy and hold, fifth column, has positive profits in 11 out of 20 cases. With respect to the other strategies, the $F C$ bands perform generally better than $R W$ and $M A_{5}$, while having similar performances to $M A_{22}$. This is due to the fact that $M A_{22}$ is able to well approximate the long-run dependence of the range series and, in this particular strategy, the difference in terms of profits is not relevant. This evidence can be well understood from Figure 3 which plots the forecasts of the range based on different model specifications. It is clear that $R W$ provides a very noisy forecast of the range, while $M A_{22}$ is extremely smooth and it is close to the forecast of the FVECM that is based on the maximum likelihood estimates of $b$, which governs the persistence of the range. Relative to the other strategies, the strategy based on FVECM has a lower number of days of trading, that is approximately 40, compared to $R W$ and $M A_{5}$, which trade more frequently. Moreover, the variance associated with the daily payoff of the various strategies is the lowest for the FVECM in 12 out of 20 cases. The variance of the buy $\&$ hold strategy, $B \& H$, is always greater than the variance of the strategies based on intradaily trading. Finally, the Sharpe ratio associated with the $F C$ strategy often takes the highest value. This means that, when the returns of the strategies are adjusted by their riskiness, the $F C$ strategy outperforms the others. This is probably due to the fact that the FVECM is able to provide good forecasts of the range, and therefore more precise timing for investments.

\section{Conclusion}

The main contribution of this paper is to show that high and low prices of equity shares are partially predictable and that future extreme prices can be forecast simply by using past high and low prices that are readily available. Apparently, their predictability is at odds with the difficulty of forecasting asset returns when prices are taken at a fixed point in time (at closing, say) and with a long tradition of empirical work (e.g. Fama (1970 and 1991)) supporting the efficient market hypothesis.

We propose to model high and low prices using a simple implementation of a fractional vector autoregressive model with error correction (FVECM). This modeling strategy is consistent with two main stylized patterns documented in this paper: first, high and low prices are cointegrated, i.e. they may temporarily diverge but they have an embedded convergent path in the long run. Second, the difference between them, i.e. the range, displays a long persistence that can be well captured by the fractional autoregressive technique.

The analysis of some simple trading strategies shows that the use of predicted high and low prices as entry and exit signals improves the investment performance. More specifically, we find that out-of-sample trading strategies based on FVECM model forecasts outperform any 
reasonable benchmark model, even on a risk-adjusted basis.

Future research might extend our work in many respects. An interesting question to address is how good predictions of high and low prices can enhance risk analysis and management. 


\section{References}

Alizadeh, S., M. W. Brandt, and F. X. Diebold (2002): "Range-Based Estimation of Stochastic Volatility Models," The Journal of Finance, Vol. 57, No. 3, pp. 1047-1091.

Allen, H., And M. P. Taylor (1990): "Charts, Noise and Fundamentals in the London Foreign Exchange Market," Economic Journal, 100(400), 49-59.

Andersen, T., And T. Bollerslev (1998): "Answering the Skeptics: Yes, Standard Volatility Models Do Provide Accurate Forecasts," International Economic Review, 39, 885-905.

Andersen, T. G., and T. Bollerslev (1997): "Heterogeneous Information Arrivals and Return Volatility Dynamics: Uncovering the Long-Run in High Frequency Returns," The Journal of Finance, 52, 975-1005.

Andersen, T. G., T. Bollerslev, F. X. Diebold, and H. Ebens (2001): "The Distribution of Stock Return Volatility," Journal of Financial Economics, 61, 43-76.

BAILliE, R. T. (1996): "Long memory processes and fractional integration in econometrics," Journal of Econometrics, 73(1), 5-59.

Ball, C. A., And W. N. Torous (1984): "1984. The maximum likelihood estimation of security price volatility: Theory, evidence, and application to option pricing," Journal of Business, 57, 97112.

Beckers, S. (1983): "Variances of Security Price Returns Based on High, Low, and Closing Prices," Journal of Business, 56(1), 97-112.

Beran, J. (1994): Statistics for Long-Memory Processes. Chapman \& Hall.

Bollerslev, T., And H. O. Mikkelsen (1996): "Modeling and pricing long memory in stock market volatility," Journal of Econometrics, 73, 151-184.

Brandt, M. W., and F. X. Diebold (2006): "A No-Arbitrage Approach to Range-Based Estimation of Return Covariances and Correlations," Journal of Business, vol. 79, no. 1, $61-73$.

Breidt, F. J., N. Crato, and P. de Lima (1998): "The detection and estimation of long memory in stochastic volatility," Journal of Econometrics, 83(1-2), 325 - 348.

Breitung, J., and U. Hassler (2002): "Inference on the cointegration rank in fractionally integrated processes," Journal of Econometrics, 110(2), 167-185.

Cheung, Y. (2007): "An empirical model of daily highs and lows," International Journal of Finance and Economics, 12, 1-20.

Christensen, B. J., J. Zhu, and M. Nielsen (2009): "Long memory in stock market volatility and the volatility-in-mean effect: the FIEGARCH-M model," Working Papers 1207, Queen's University, Department of Economics.

Christensen, K., And M. Podolskij (2007): "Realized Range Based Estimation of Integrated Variance," Journal of Econometrics, 141, 323-349.

Curcio, R., and C. Goodhart (1992): "When Support/Resistance Levels are Broken, Can Profits be Made? Evidence from the Foreign Exchange Market," FMG Discussion Papers dp142, Financial Markets Group. 
Dacorogna, M., U. A. Muller, R. J. Nagler, R. B. Olsen, and O. V. Pictet (1993): "A geographical model for the daily and weekly seasonal volatility in the foreign exchange market," Journal of International Money and Finance, 12, 413-438.

Davidson, J., And N. Hashimzade (2009): "Type I and type II fractional Brownian motions: A reconsideration," Computational Statistics \& Data Analysis, 53(6), 2089-2106.

DeGrauwe, P., and D. Decupere (1992): "Psychological Barriers in the Foreign Exchange Markets," Journal of international and comparative economics, 1, 87-101.

Diebold, F. X., and R. S. Mariano (1995): "Comparing Predictive Accuracy," Journal of Business \& Economic Statistics, 13(3), 253-63.

Diebold, F. X., and G. D. Rudebusch (1991): "On the power of Dickey-Fuller tests against fractional alternatives," Economics Letters, 35(2), 155-160.

Ding, Z., C. Granger, and R. Engle (1993): "A Long Memory Property of stock Market Returns and a New Model," Journal of Empirical Finance, 1, 83-106.

Engle, R., And C. Granger (1987): "Cointegration and error correction: representation estimation, and testing," Econometrica, 55, 251276.

Engle, R. F. (1982): "Autoregressive Conditional Heteroscedasticity with Estimates of the Variance of United Kingdom Inflation," Econometrica, 50, 987-1008.

FAma, E. F. (1970): "Efficient Capital Markets: A Review of Theory and Empirical Work," Journal of Finance, 25(2), 383-417.

_ (1991): "Efficient Capital Markets: II," Journal of Finance, 46(5), 1575-617.

FELLER, W. (1951): "The asympotic distribution of the range of sums of independent random variables," Annals of Mathematical Statistics, 22, 427-432.

Gallant, A. R., C.-T. Hsu, and G. Tauchen (1999): "Using Daily Range Data to Calibrate Volatility Diffusions and Extract the Forward Integrated Variance," The Review of Economics and Statistics, 84, No. 4., 617-631.

Garman, M. B., and M. J. Klass (1980): "On the Estimation of Security Price Volatilities from Historical Data," Source: The Journal of Business, Vol. 53, No. 1, 67-78.

Granger, C., And Z. Ding (1996): "Modeling volatility persistence of speculative returns," Journal of Econometrics, 73, 185-215.

Granger, C. W. J. (1981): "Some properties of time series data and their use in econometric model specification," Journal of Econometrics, 16, 121130.

Hualde, J., And P. Robinson (2010): "Semiparametric inference in multivariate fractionally cointegrated systems," Journal of Econometrics, 157, 492-511.

Johansen, S. (1991): "Estimation and Hypothesis Testing of Cointegration Vectors in Gaussian Vector Autoregressive Models," Econometrica, 59(6), 1551-80.

(2008): "A representation theory for a class of vector autoregressive models for fractional processes," Econometric Theory, Vol 24, 3, 651-676.

Johansen, S., And M. Ø. Nielsen (2010a): "Likelihood inference for a fractionally cointegrated vector autoregressive model," CREATES Research Papers 2010-24, School of Economics and Management, University of Aarhus. 
Johansen, S., And M. Ø. NiELSEn (2010b): "Likelihood inference for fractionally cointegrated vector autoregressive model," Discussion paper, CREATES, University of Aarhus.

(2011): "Likelihood inference for a fractionally cointegrated vector autoregressive model," Discussion paper, University of Aarhus.

Kahneman, D., and A. Tversky (1979): "Prospect Theory: An Analysis of Decision under Risk," Econometrica, 47(2), 263-91.

Kavajecz, K. A., and E. R. Odders-White (2004): "Technical Analysis and Liquidity Provision," Review of Financial Studies, 17, 1043-1071.

Kunitomo, N. (1992): "Improving the Parkinson Method of Estimating Security Price Volatilities," Journal of Business, 65(2), 295-302.

LASAK, K. (2008): "Maximum likelihood estimation of fractionally cointegrated systems," Discussion paper, CREATES Research Paper 2008-53.

Lim, K., AND R. Brooks (2011): "The evolution of stock market efficiency over time: a survey of the empirical literature," Journal of Economic Surveys, 25, 69-108.

Lo, A. W., H. Mamaysky, and J. Wang (2000): "Foundations of Technical Analysis: Computational Algorithms, Statistical Inference, and Empirical Implementation," Journal of Finance, 55(4), 1705-1770.

Marinucci, D., And P. M. Robinson (1999): "Alternative Forms of Fractional Brownian Motion," Journal of Statistical Planning and Inference, 80, 111-122.

Martens, M., And D. van DiJk (2007): "Measuring volatility with the realized range," Journal of Econometrics, 138, 181-207.

Menkhoff, L. (1998): "The noise trading approach - questionnaire evidence from foreign exchange," Journal of International Money and Finance, 17(3), 547-564.

Murphy, J. (1999): Technical Analysis of the Financial Markets. Prentice Hall Press.

Nielsen, M. Ø. (2005): "Multivariate Lagrange Multiplier Tests for Fractional Integration," Journal of Financial Econometrics, 3(3), 372-398.

Nielsen, M. Ø., And K. Shimotsu (2007): "Determining the cointegration rank in nonstationary fractional system by the exact local Whittle approach," Journal of Econometrics, 141, $574-596$.

OsLer, C. (2000): "Support for resistance: technical analysis and intraday exchange rates," Economic Policy Review, (Jul), 53-68.

Parkinson, M. (1980): "The Extreme Value Method for Estimating the Variance of the Rate of Return," The Journal of Business, 53, 61-65.

Robinson, P. M., and Y. Yajima (2002): "Determination of cointegrating rank in fractional systems," Journal of Econometrics, 106, 217-241.

Rogers, L., And S. SATchell (1991): "Estimating variance from high, low and closing prices," Annals of Applied Probability, 1, 504-512.

Rossi, E., And P. Santucci de Magistris (2009): "A No Arbitrage Fractional Cointegration Analysis Of The Range Based Volatility," Discussion paper, University of Pavia, Italy. 
Shimotsu, K., And P. Phillips (2005): "Exact local Whittle estimation of fractional integration.," Annals of Statistics, 33, 1890-1933.

Yang, D., And Q. Zhang (2000): "Drift-Independent Volatility Estimation Based on High, Low, Open, and Close Prices," Journal of Business, 73(3), 477-91. 

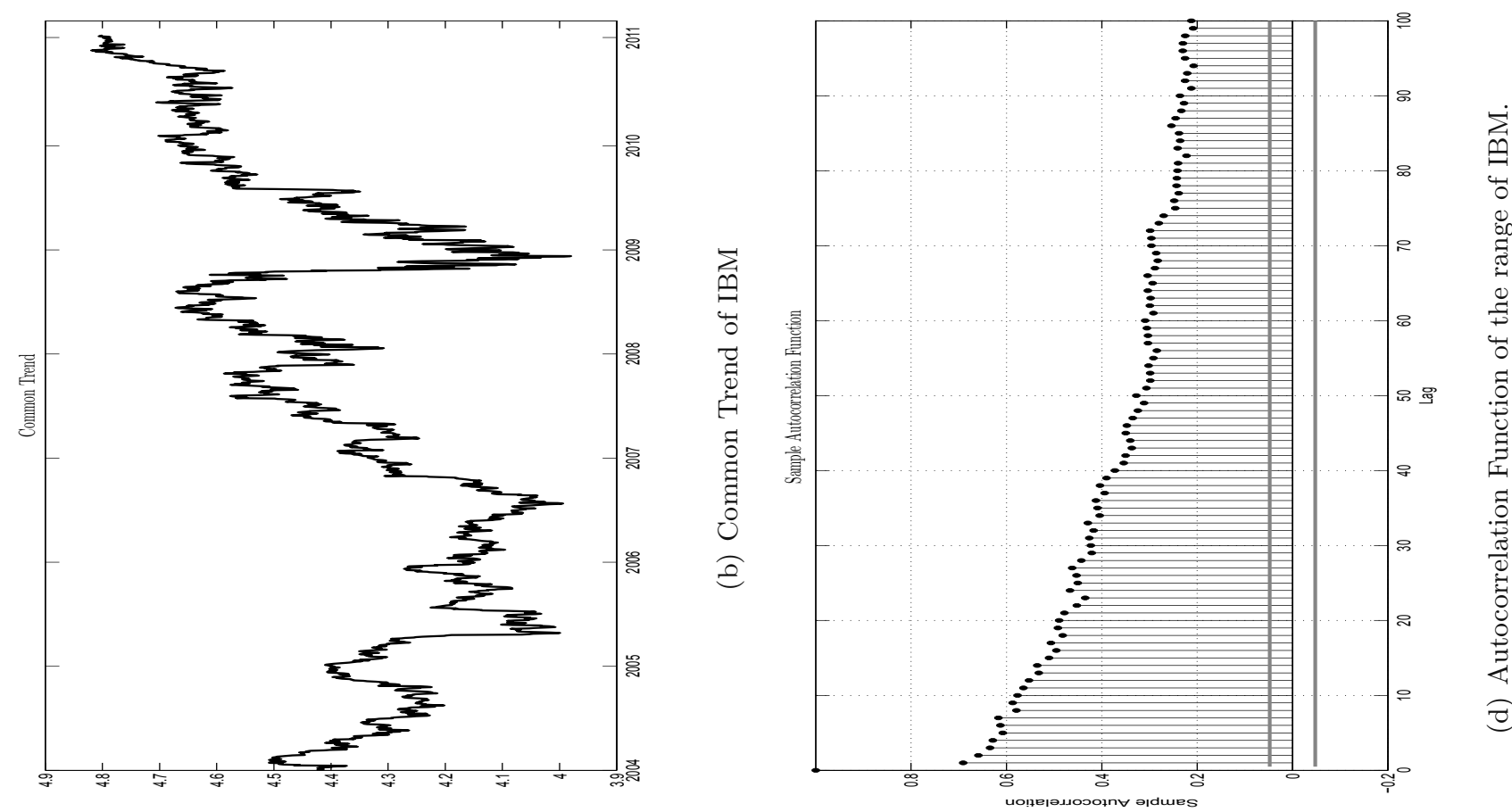

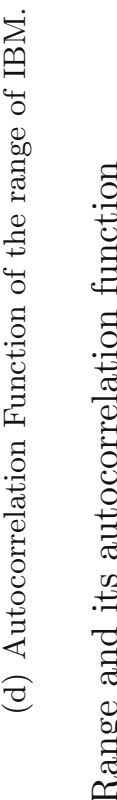
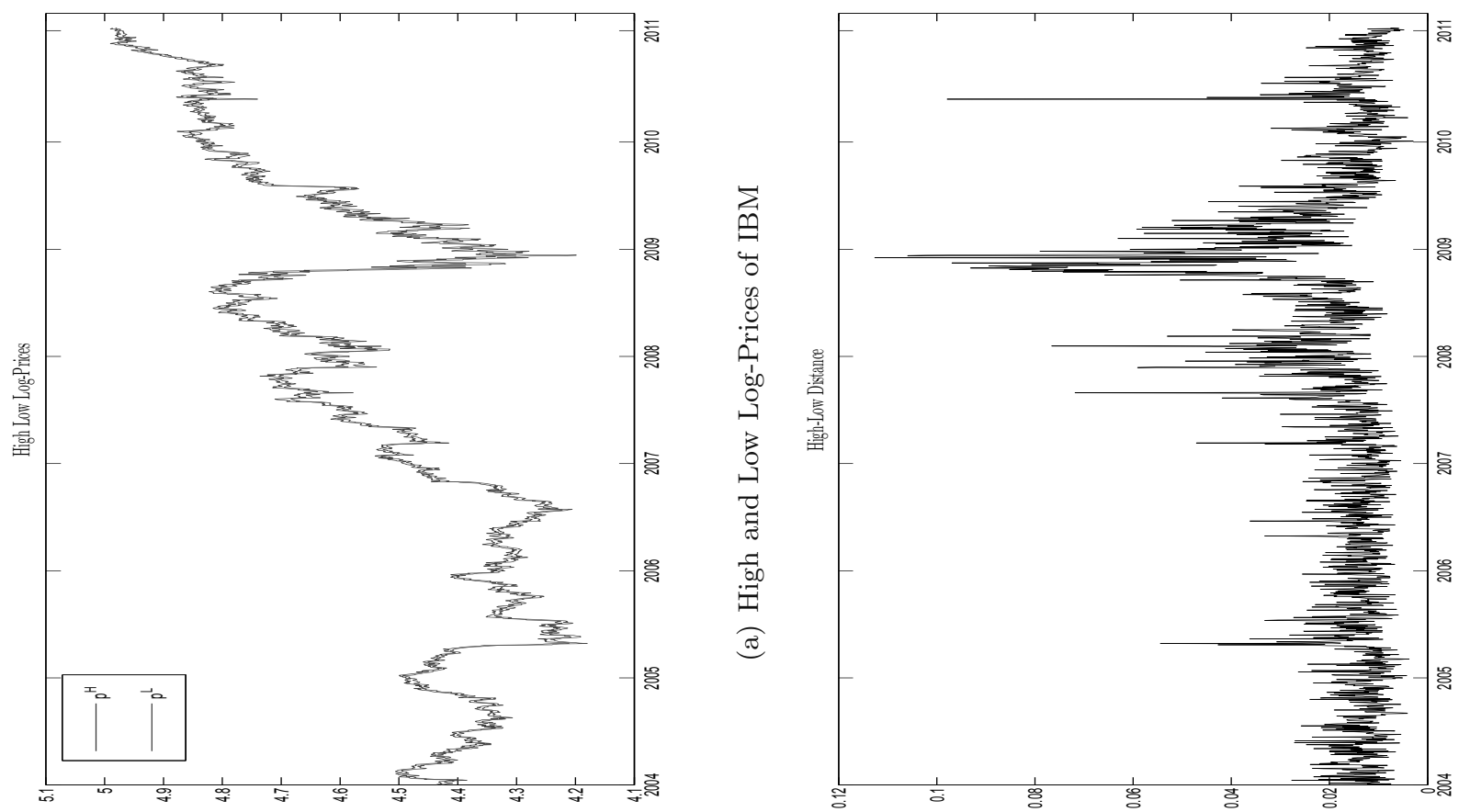


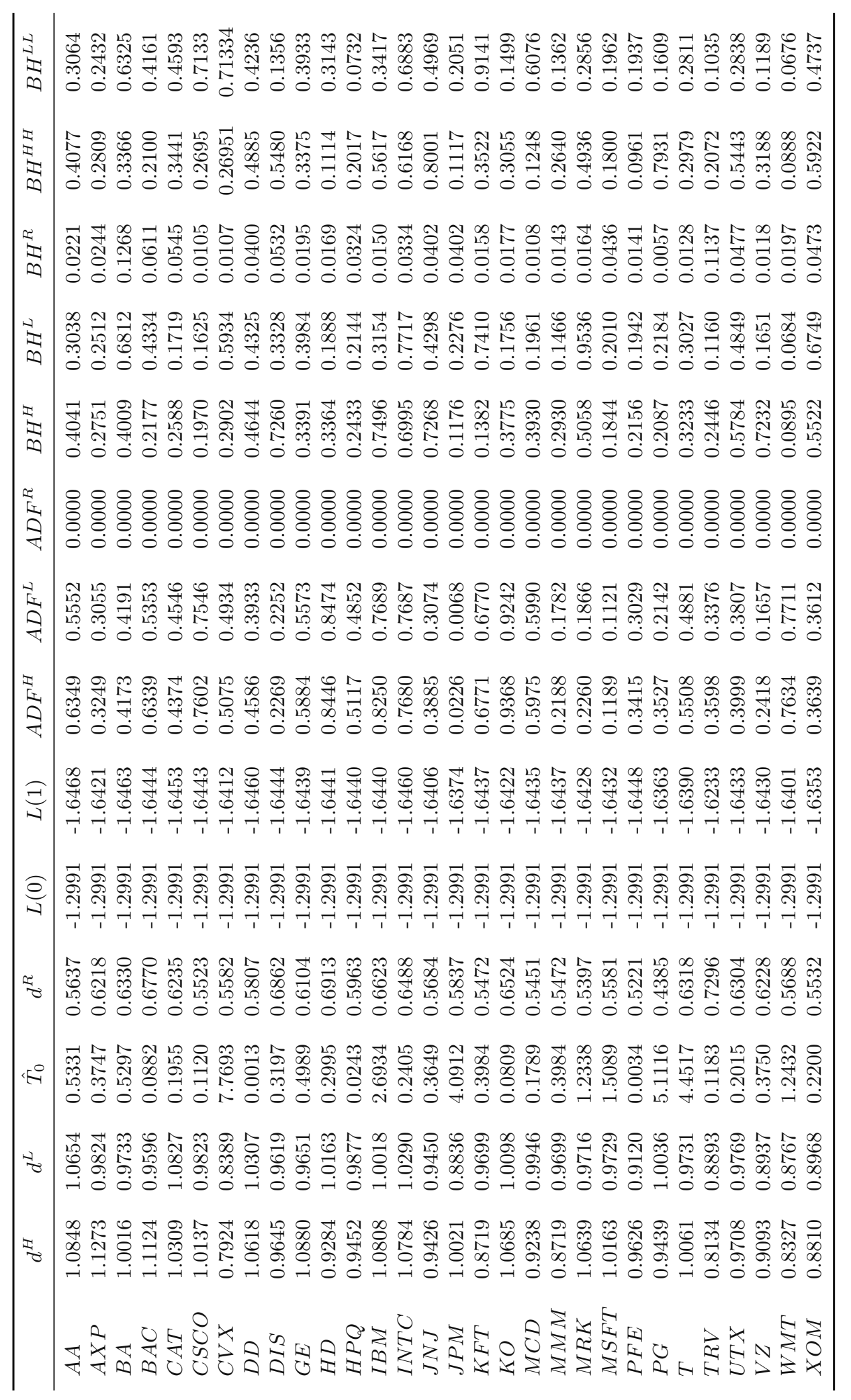

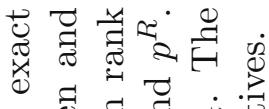

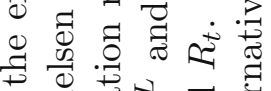

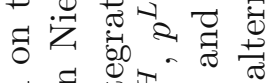

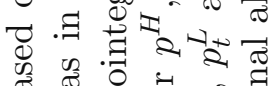

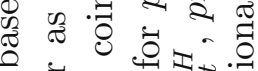

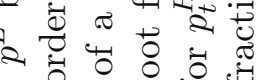

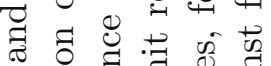
记 2. o 40 .

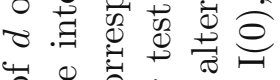

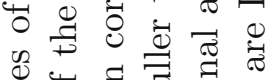
证

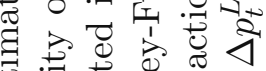
봉 D.

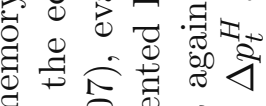
bo 营过

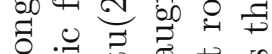

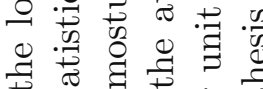

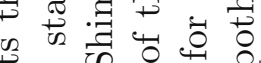

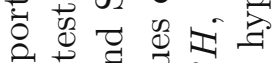

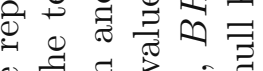

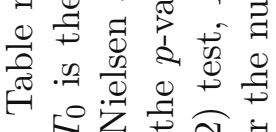

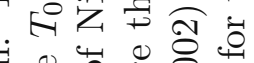
.

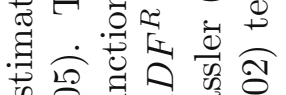

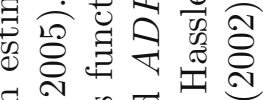
웡 क

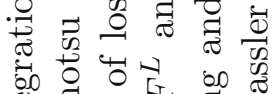

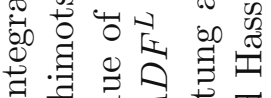
苨 สี

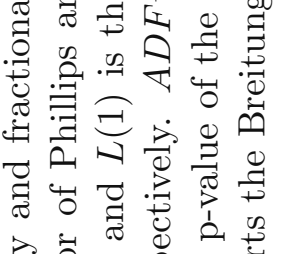
:

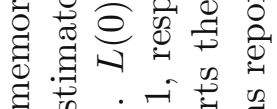

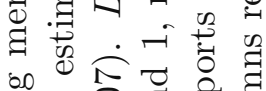
of

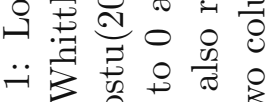
等

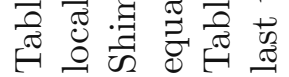




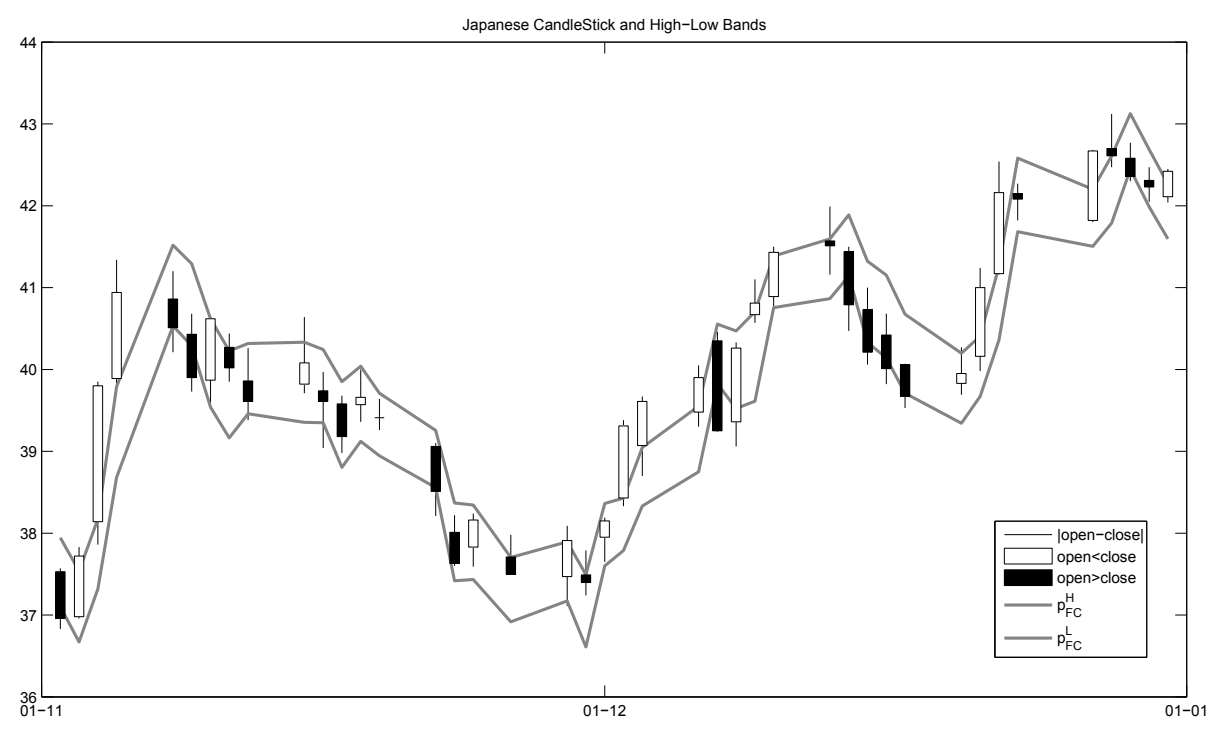

(a) FC bands

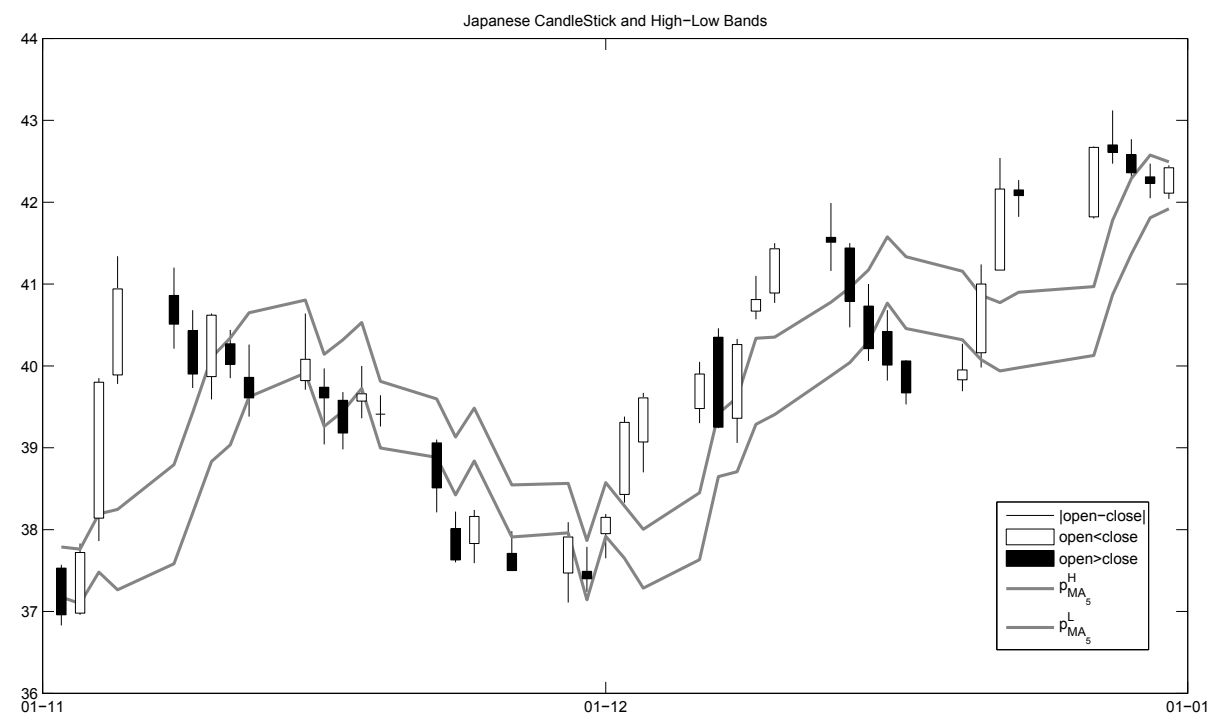

(b) $\mathrm{MA}_{5}$ bands

Figure 2: Japanese CandleStick with predicted high-low bands. Panel a), the red lines are the high-low band based on model (10). Panel b) the red lines are the high-low bands based on the 5 days moving average. The sample covers the period from November 1, 2010 to December 31, 2010 . 

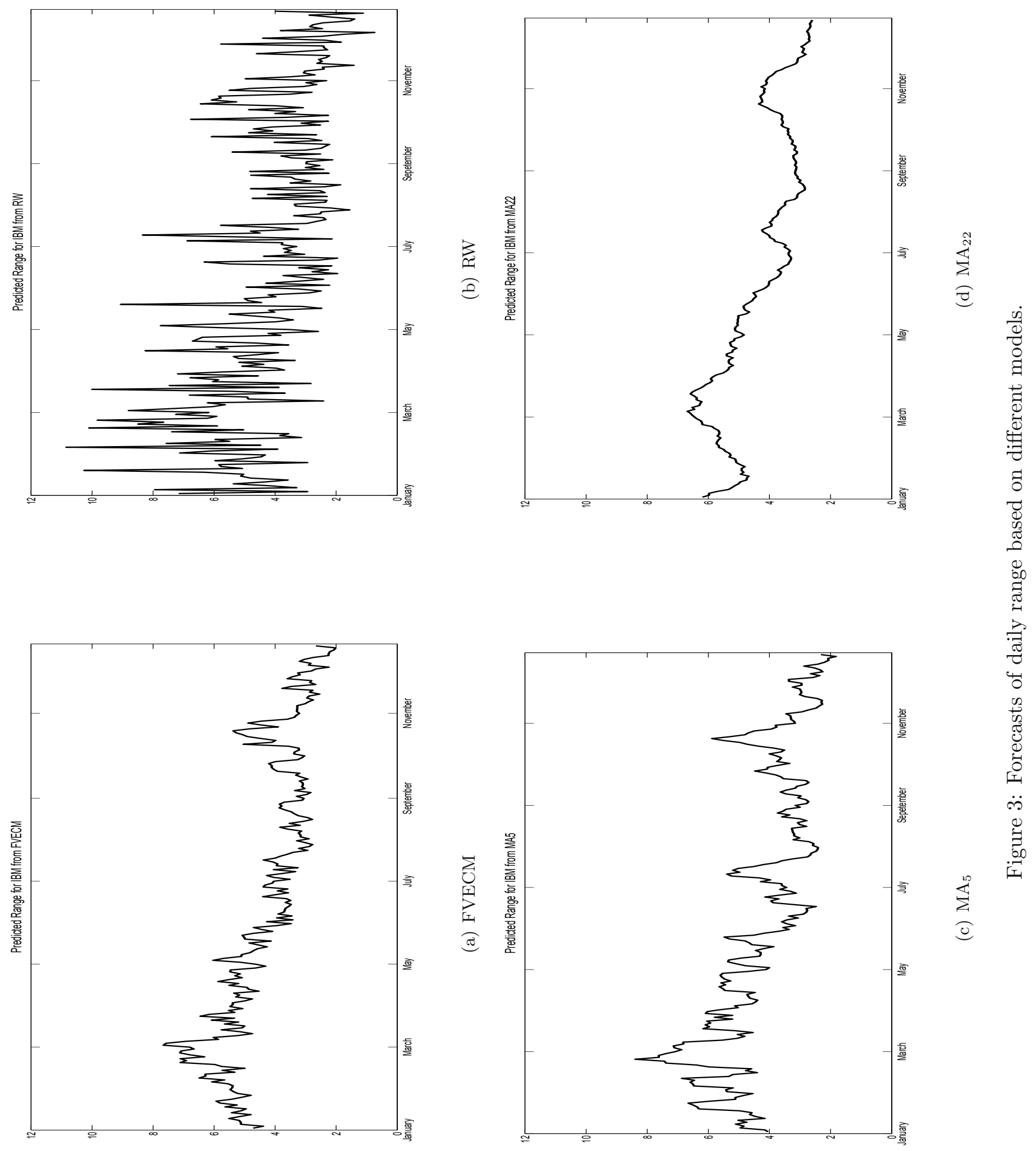


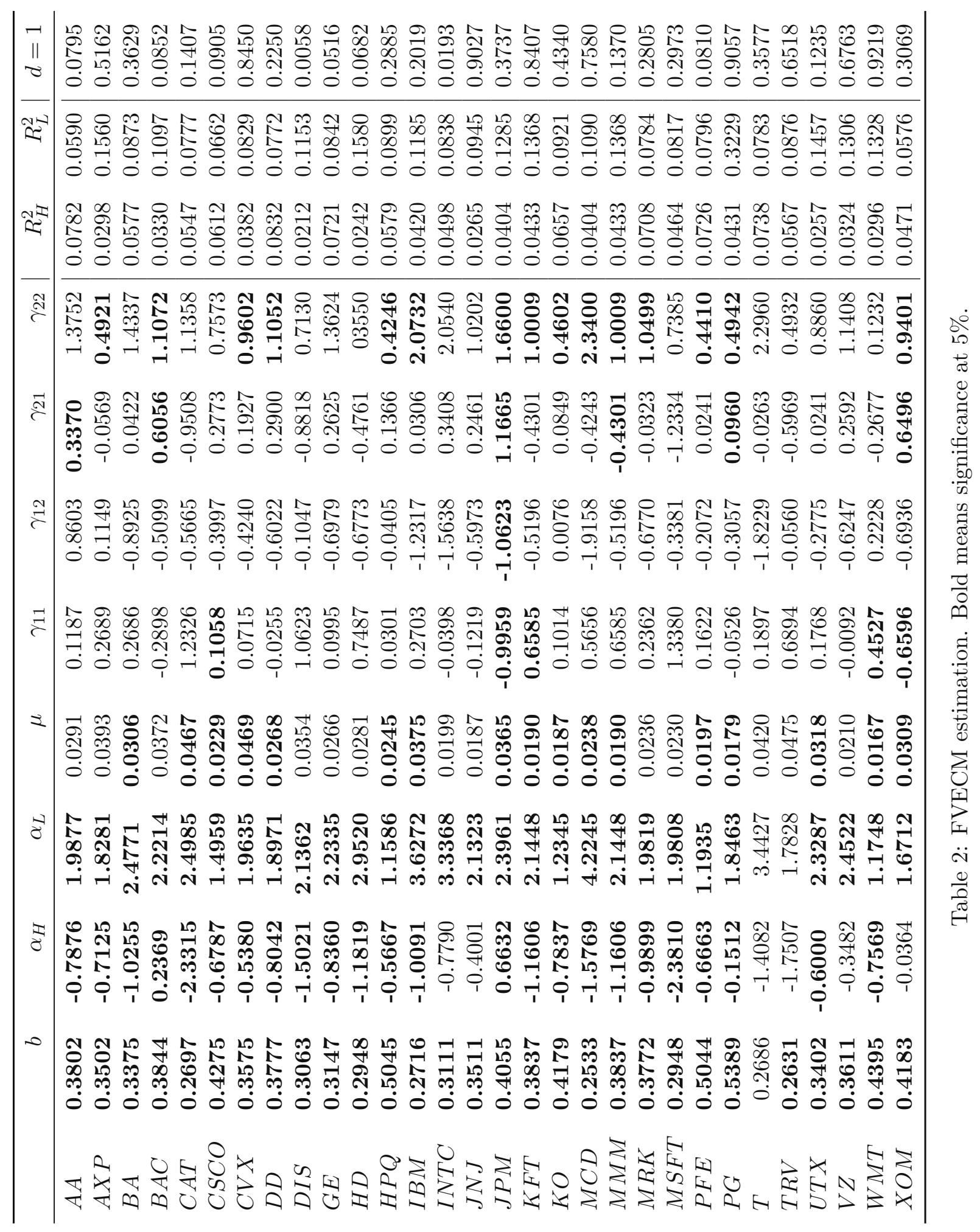




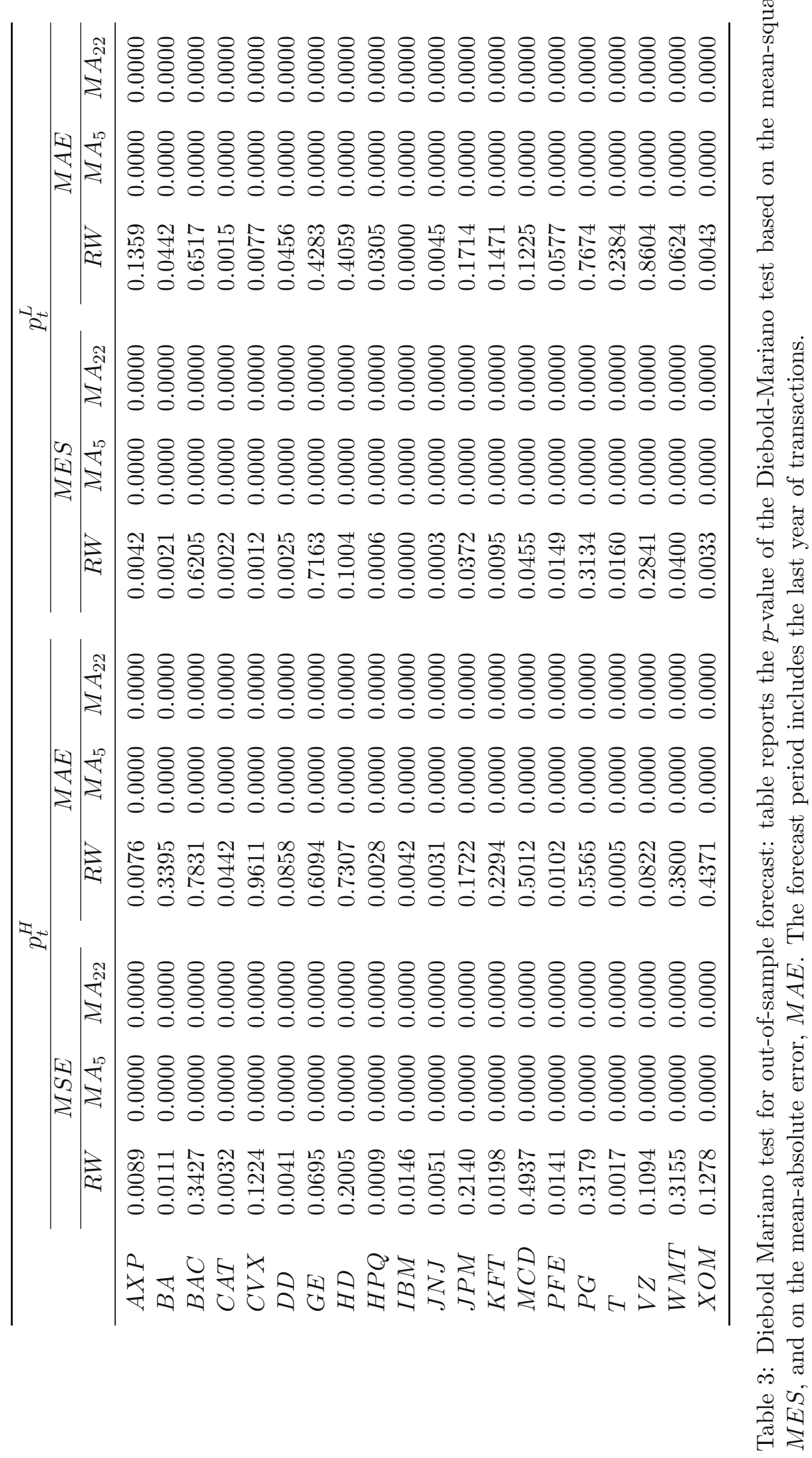




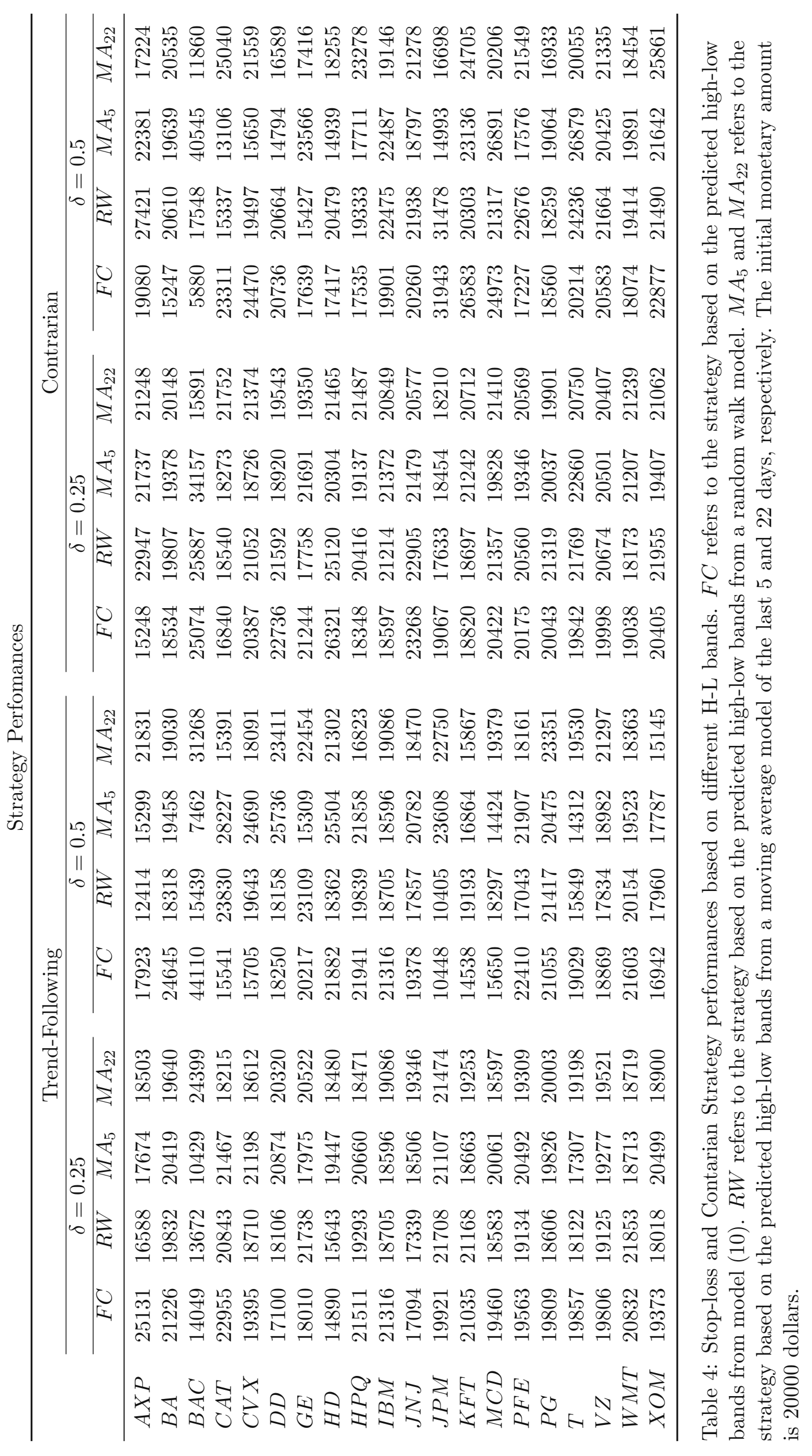




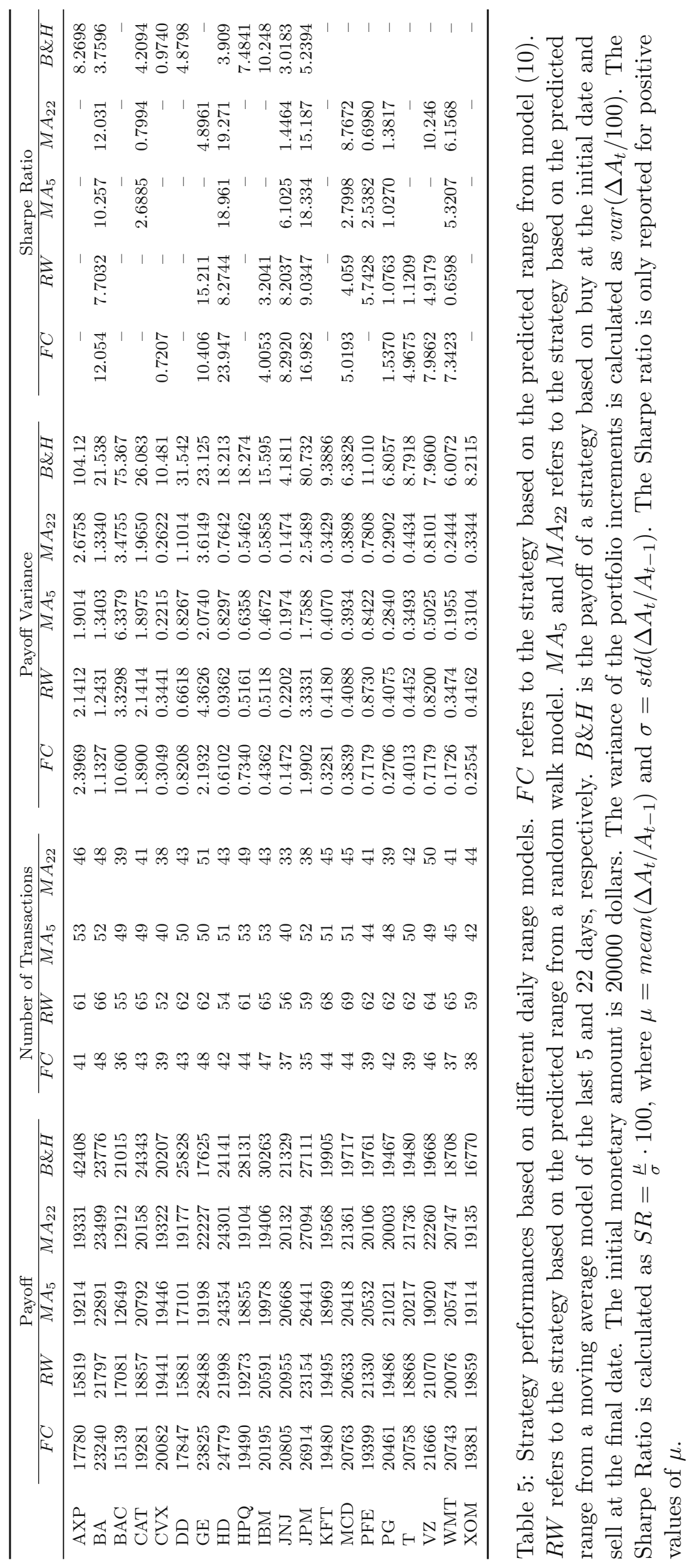


Swiss National Bank Working Papers published since 2004:

2004-1 Samuel Reynard: Financial Market Participation and the Apparent Instability of Money Demand

2004-2 Urs W. Birchler and Diana Hancock: What Does the Yield on Subordinated Bank Debt Measure?

2005-1 Hasan Bakhshi, Hashmat Khan and Barbara Rudolf: The Phillips curve under state-dependent pricing

2005-2 Andreas M. Fischer: On the Inadequacy of Newswire Reports for Empirical Research on Foreign Exchange Interventions

2006-1 Andreas M. Fischer: Measuring Income Elasticity for Swiss Money Demand: What do the Cantons say about Financial Innovation?

2006-2 Charlotte Christiansen and Angelo Ranaldo: Realized Bond-Stock Correlation: Macroeconomic Announcement Effects

2006-3 Martin Brown and Christian Zehnder: Credit Reporting, Relationship Banking, and Loan Repayment

2006-4 Hansjörg Lehmann and Michael Manz: The Exposure of Swiss Banks to Macroeconomic Shocks - an Empirical Investigation

2006-5 Katrin Assenmacher-Wesche and Stefan Gerlach: Money Growth, Output Gaps and Inflation at Low and High Frequency: Spectral Estimates for Switzerland

2006-6 Marlene Amstad and Andreas M. Fischer: Time-Varying Pass-Through from Import Prices to Consumer Prices: Evidence from an Event Study with Real-Time Data

2006-7 Samuel Reynard: Money and the Great Disinflation

2006-8 Urs W. Birchler and Matteo Facchinetti: Can bank supervisors rely on market data? A critical assessment from a Swiss perspective

2006-9 Petra Gerlach-Kristen: A Two-Pillar Phillips Curve for Switzerland

2006-10 Kevin J. Fox and Mathias Zurlinden: On Understanding Sources of Growth and Output Gaps for Switzerland

2006-11 Angelo Ranaldo: Intraday Market Dynamics Around Public Information Arrivals

2007-1 Andreas M. Fischer, Gulzina Isakova and Ulan Termechikov: Do FX traders in Bishkek have similar perceptions to their London colleagues? Survey evidence of market practitioners' views 
2007-2 Ibrahim Chowdhury and Andreas Schabert: Federal Reserve Policy viewed through a Money Supply Lens

2007-3 Angelo Ranaldo: Segmentation and Time-of-Day Patterns in Foreign Exchange Markets

2007-4 Jürg M. Blum: Why ‘Basel II' May Need a Leverage Ratio Restriction

2007-5 Samuel Reynard: Maintaining Low Inflation: Money, Interest Rates, and Policy Stance

2007-6 Rina Rosenblatt-Wisch: Loss Aversion in Aggregate Macroeconomic Time Series

2007-7 Martin Brown, Maria Rueda Maurer, Tamara Pak and Nurlanbek Tynaev: Banking Sector Reform and Interest Rates in Transition Economies: Bank-Level Evidence from Kyrgyzstan

2007-8 Hans-Jürg Büttler: An Orthogonal Polynomial Approach to Estimate the Term Structure of Interest Rates

2007-9 Raphael Auer: The Colonial Origins Of Comparative Development: Comment. A Solution to the Settler Mortality Debate

2007-10 Franziska Bignasca and Enzo Rossi: Applying the Hirose-Kamada filter to Swiss data: Output gap and exchange rate pass-through estimates

2007-11 Angelo Ranaldo and Enzo Rossi: The reaction of asset markets to Swiss National Bank communication

2007-12 Lukas Burkhard and Andreas M. Fischer: Communicating Policy Options at the Zero Bound

2007-13 Katrin Assenmacher-Wesche, Stefan Gerlach, and Toshitaka Sekine: Monetary Factors and Inflation in Japan

2007-14 Jean-Marc Natal and Nicolas Stoffels: Globalization, markups and the natural rate of interest

2007-15 Martin Brown, Tullio Jappelli and Marco Pagano: Information Sharing and Credit: Firm-Level Evidence from Transition Countries

2007-16 Andreas M. Fischer, Matthias Lutz and Manuel Wälti: Who Prices Locally? Survey Evidence of Swiss Exporters

2007-17 Angelo Ranaldo and Paul Söderlind: Safe Haven Currencies 
2008-1 Martin Brown and Christian Zehnder: The Emergence of Information Sharing in Credit Markets

2008-2 Yvan Lengwiler and Carlos Lenz: Intelligible Factors for the Yield Curve

2008-3 Katrin Assenmacher-Wesche and M. Hashem Pesaran: Forecasting the Swiss Economy Using VECX* Models: An Exercise in Forecast Combination Across Models and Observation Windows

2008-4 Maria Clara Rueda Maurer: Foreign bank entry, institutional development and credit access: firm-level evidence from 22 transition countries

2008-5 Marlene Amstad and Andreas M. Fischer: Are Weekly Inflation Forecasts Informative?

2008-6 Raphael Auer and Thomas Chaney: Cost Pass Through in a Competitive Model of Pricing-to-Market

2008-7 Martin Brown, Armin Falk and Ernst Fehr: Competition and Relational Contracts: The Role of Unemployment as a Disciplinary Device

2008-8 Raphael Auer: The Colonial and Geographic Origins of Comparative Development

2008-9 Andreas M. Fischer and Angelo Ranaldo: Does FOMC News Increase Global FX Trading?

2008-10 Charlotte Christiansen and Angelo Ranaldo: Extreme Coexceedances in New EU Member States' Stock Markets

2008-11 Barbara Rudolf and Mathias Zurlinden: Measuring capital stocks and capital services in Switzerland

2008-12 Philip Sauré: How to Use Industrial Policy to Sustain Trade Agreements

2008-13 Thomas Bolli and Mathias Zurlinden: Measuring growth of labour quality and the quality-adjusted unemployment rate in Switzerland

2008-14 Samuel Reynard: What Drives the Swiss Franc?

2008-15 Daniel Kaufmann: Price-Setting Behaviour in Switzerland - Evidence from CPI Micro Data

2008-16 Katrin Assenmacher-Wesche and Stefan Gerlach: Financial Structure and the Impact of Monetary Policy on Asset Prices

2008-17 Ernst Fehr, Martin Brown and Christian Zehnder: On Reputation: A Microfoundation of Contract Enforcement and Price Rigidity 
2008-18 Raphael Auer and Andreas M. Fischer: The Effect of Low-Wage Import Competition on U.S. Inflationary Pressure

2008-19 Christian Beer, Steven Ongena and Marcel Peter: Borrowing in Foreign Currency: Austrian Households as Carry Traders

2009-1 Thomas Bolli and Mathias Zurlinden: Measurement of labor quality growth caused by unobservable characteristics

2009-2 Martin Brown, Steven Ongena and Pinar Yeșin: Foreign Currency Borrowing by Small Firms

2009-3 Matteo Bonato, Massimiliano Caporin and Angelo Ranaldo: Forecasting realized (co)variances with a block structure Wishart autoregressive model

2009-4 Paul Söderlind: Inflation Risk Premia and Survey Evidence on Macroeconomic Uncertainty

2009-5 Christian Hott: Explaining House Price Fluctuations

2009-6 Sarah M. Lein and Eva Köberl: Capacity Utilisation, Constraints and Price Adjustments under the Microscope

2009-7 Philipp Haene and Andy Sturm: Optimal Central Counterparty Risk Management

2009-8 Christian Hott: Banks and Real Estate Prices

2009-9 Terhi Jokipii and Alistair Milne: Bank Capital Buffer and Risk Adjustment Decisions

2009-10 Philip Sauré: Bounded Love of Variety and Patterns of Trade

2009-11 Nicole Allenspach: Banking and Transparency: Is More Information Always Better?

2009-12 Philip Sauré and Hosny Zoabi: Effects of Trade on Female Labor Force Participation

2009-13 Barbara Rudolf and Mathias Zurlinden: Productivity and economic growth in Switzerland 1991-2005

2009-14 Sébastien Kraenzlin and Martin Schlegel: Bidding Behavior in the SNB's Repo Auctions

2009-15 Martin Schlegel and Sébastien Kraenzlin: Demand for Reserves and the Central Bank's Management of Interest Rates

2009-16 Carlos Lenz and Marcel Savioz: Monetary determinants of the Swiss franc 
2010-1 Charlotte Christiansen, Angelo Ranaldo and Paul Söderlind: The Time-Varying Systematic Risk of Carry Trade Strategies

2010-2 Daniel Kaufmann: The Timing of Price Changes and the Role of Heterogeneity

2010-3 Loriano Mancini, Angelo Ranaldo and Jan Wrampelmeyer: Liquidity in the Foreign Exchange Market: Measurement, Commonality, and Risk Premiums

2010-4 Samuel Reynard and Andreas Schabert: Modeling Monetary Policy

2010-5 Pierre Monnin and Terhi Jokipii: The Impact of Banking Sector Stability on the Real Economy

2010-6 Sébastien Kraenzlin and Thomas Nellen: Daytime is money

2010-7 Philip Sauré: Overreporting 0il Reserves

2010-8 Elizabeth Steiner: Estimating a stock-flow model for the Swiss housing market

2010-9 Martin Brown, Steven Ongena, Alexander Popov, and Pinar Yeșin: Who Needs Credit and Who Gets Credit in Eastern Europe?

2010-10 Jean-Pierre Danthine and André Kurmann: The Business Cycle Implications of Reciprocity in Labor Relations

2010-11 Thomas Nitschka: Momentum in stock market returns: Implications for risk premia on foreign currencies

2010-12 Petra Gerlach-Kristen and Barbara Rudolf: Macroeconomic and interest rate volatility under alternative monetary operating procedures

2010-13 Raphael Auer: Consumer Heterogeneity and the Impact of Trade Liberalization: How Representative is the Representative Agent Framework?

2010-14 Tommaso Mancini Griffoli and Angelo Ranaldo: Limits to arbitrage during the crisis: funding liquidity constraints and covered interest parity

2010-15 Jean-Marc Natal: Monetary Policy Response to Oil Price Shocks

2010-16 Kathrin Degen and Andreas M. Fischer: Immigration and Swiss House Prices

2010-17 Andreas M. Fischer: Immigration and large banknotes

2010-18 Raphael Auer: Are Imports from Rich Nations Deskilling Emerging Economies? Human Capital and the Dynamic Effects of Trade 
2010-19 Jean-Pierre Danthine and John B. Donaldson: Executive Compensation: A General Equilibrium Perspective

2011-1 Thorsten Beck and Martin Brown: Which Households Use Banks? Evidence from the Transition Economies

2011-2 Martin Brown, Karolin Kirschenmann and Steven Ongena: Foreign Currency Loans Demand or Supply Driven?

2011-3 Victoria Galsband and Thomas Nitschka: Foreign currency returns and systematic risks

2011-4 Francis Breedon and Angelo Ranaldo: Intraday patterns in FX returns and order flow

2011-5 Basil Guggenheim, Sébastien Kraenzlin and Silvio Schumacher: Exploring an uncharted market: Evidence on the unsecured Swiss franc money market

2011-6 Pamela Hall: Is there any evidence of a Greenspan put?

2011-7 Daniel Kaufmann and Sarah Lein: Sectoral Inflation Dynamics, Idiosyncratic Shocks and Monetary Policy

2011-8 Iva Cecchin: Mortgage Rate Pass-Through in Switzerland

2011-9 Raphael A. Auer, Kathrin Degen and Andreas M. Fischer: Low-Wage Import Competition, Inflationary Pressure, and Industry Dynamics in Europe

2011-10 Raphael A. Auer and Philip Sauré: Spatial Competition in Quality, Demand-Induced Innovation, and Schumpeterian Growth

2011-11 Massimiliano Caporin, Angelo Ranaldo and Paolo Santucci de Magistris: On the Predictability of Stock Prices: a Case for High and Low Prices 
Swiss National Bank Working Papers are also available at www.snb.ch, section Publications/Research Subscriptions or individual issues can be ordered at Swiss National Bank, Fraumünsterstrasse 8, CH-8022 Zurich, fax+41 4463181 14, E-mail library@snb.ch 